\title{
Competition with Forward Contracts: A Laboratory Analysis Motivated by Electricity Market Design*
}

\author{
By
}

\author{
Jordi Brandts ${ }^{\#}$ Paul Pezanis-Christou ${ }^{\#}$ and Arthur Schram ${ }^{+}$
}

July 2003

\begin{abstract}
We use experiments to study the efficiency effects for a market as a whole of adding the possibility of forward contracting to a pre-existing spot market. We deal separately with the cases where spot market competition is in quantities and where it is in supply functions. In both cases we compare the effect of adding a contract market with the introduction of an additional competitor, changing the market structure from a triopoly to a quadropoly. We find that, as theory suggests, for both types of competition the introduction of a forward market significantly lowers prices. The combination of supply function competition with a forward market leads to high efficiency levels.
\end{abstract}

Keywords: Electricity Markets, Forward Markets, Experiments, Competition

JEL Classification Numbers: C92, D43, L11, L94

${ }^{\#}$ Institut d'Anàlisi Econòmica (CSIC), Campus UAB, 08193 Bellaterra, Barcelona, Spain. email Brandts:

Jordi.Brandts@uab.es; email Pezanis-Christou:ppc@iae.csic.es

${ }^{+}$CREED, Universiteit van Amsterdam, Roetersstraat 11, 1018 EB Amsterdam, the Netherlands. email:

Arthurs@fee.uva.nl

* Financial support by the European Union through the TMR research network ENDEAR (FMRX-CT98-0238) and the Spanish Ministerio de Ciencia y Tecnología (SEC2002-01352) is gratefully acknowledged. We thank Ed Kahn, Tanga McDaniel, Steve Rassenti, Robert Wilson, participants at the Seventh Annual Power Conference in Berkeley and at the ESA Conference in Strasbourg for helpful comments. 



\section{Introduction}

In the world-wide process of regulatory reform in the electricity industry, the mitigation of market power is one of the basic problems regulators have to deal with. Experiments are currently being used to study a variety of issues related to the efficient organization of these markets. Rassenti et al. (2002) discuss the advantages of using experiments for studying electric power markets. Rassenti et al. (2000a), Weiss (2002) and Staropoli et al. (2000) use experiments to study several aspects of the exercise of market power and how it can be limited. Rassenti et al. (2001) and Abbink et al. (2003) compare prices and efficiency levels under the uniform and the discriminatory price call auctions and find that the first auction format has more desirable properties. As in other contexts, experiments allow for a very controlled investigation of behavior under different institutional settings. In this paper we use experiments to study the effects of adding a forward contract market to an imperfectly competitive spot market.

The original rationale for the existence of forward markets is related to the hedging of risk. An influential study by Allaz and Vila (1993) added a second rationale. They show that the presence of a forward market changes producers' strategic incentives in a way which, in equilibrium, enhances competition and efficiency. In this paper we leave aside uncertainty considerations and focus purely on the implications of forward trading for strategic behavior. The strategic consequence of allowing for the presence of forward contracting consists in committing firms to more aggressive output decisions. Selling decisions on the forward market involve a kind of dilemma game. If just one firm sells forward it obtains a Stackelberg-type advantage, but if all firms pre-commit then they are all worse off in terms of their economic profits. The focus of our study will, hence, be on the comparison of efficiency and output levels across different institutional arrangements and on the analysis of behavior in this dilemma-type situation.

The analysis we present here is based on stylized representations of the actual workings of the relevant markets. We study both the case where spot market competition is in quantities and the case where it is in supply functions. As shown below, this will yield a rather complete picture of behavior. Our results show that the introduction of forward markets increases the quantity supplied as well as efficiency. However, even higher quantities (but not efficiency) are observed in case competition is increased by adding one producer to the market instead of introducing a forward market.

The paper is organized as follows. In the next section we discuss the relation between electricity markets and our experimental design. We also discuss the existing theoretical literature. Section 3 gives the experimental design and procedures. In section 4 we derive predictions and hypotheses and in section 5 we present our results. Section 6 concludes the paper. 


\section{From electricity markets to experiments}

Because our analysis is motivated by issues of market performance in the electric power industry, we want our design to take account of some of the central features of those markets. Of course, the most important element in our experiments is that we study the effects of introducing forward markets. ${ }^{1}$ For this purpose, we compare experimental markets with and without forward trading. There are, however, additional links between the structure of the electricity markets and that of our experiments. We discuss those links in this section and relate them to the relevant theoretical literature. Specific details about how various choices about the structure of the experiments are implemented are discussed in section 3.

First of all, the rules that govern spot market competition in the electric power industry are not well represented by quantity competition but correspond more closely to supply function competition as introduced by Klemperer and Meyer (1989). Examples are the spot markets for electricity in Australia, Chili, England and Wales, New Zealand, Scandinavia and Spain. In those markets firms typically submit multiple bid-quantity combinations.

However, the quantity competition model yields distinct theoretical predictions, whereas supply function competition typically implies multiple equilibria. Allaz and Vila (1993) and Bolle (1993) study the effects of forward contracting for the case in which spot market competition is in quantities. For this case they provide unique predictions. For supply function competition without forward markets, Klemperer and Meyer show that there is a continuum of equilibria; it is possible to obtain a unique equilibrium once a specific type of demand uncertainty is introduced. (See also, Rudkevich (1998), Baldrick, Grant and Kahn (2000) and Bolle (2001)). Newbery (1998) and Green (1999) present models combining forward markets with supply function competition in the spot market. They base their analysis on different restrictions on functional forms and also need demand uncertainty to obtain a unique prediction.

Given that we want to focus on the strategic aspects related to the introduction of forward markets, we chose not to impose demand uncertainty in our experiments. This leaves us without a clear theoretical benchmark for the supply function case. For this reason, in our experiments we study both types of competition in parallel. The advantage of including quantity competition in our design is that they can be used as a kind of anchor, providing our supply function treatments with an indirect connection to theoretical predictions. At the same time, our design will enable us to see whether behavior under quantity competition is a good approximation for what one observes for the case of supply functions.

\footnotetext{
${ }^{1}$ Le Coq and Ortzen (2002) present experimental results on the strategic effect of forward markets. However, their design is not related to electricity markets. They simulate the contract market and deal exclusively with quantity competition with marginal costs equal to zero. Miller et al. (1977), Hoffman and Plott (1981) and Williams and Smith (1984) report on some other experiments in which some participants act as traders arbitraging between different time periods.
} 
A second basic decision we need to make in the step from electricity markets to an experimental framework concerns the numbers of producers and (in case of forward markets) of traders. A number of experimental studies have dealt with quantity competition without forward markets (Binger et al., 1992, Huck et al., 1999, Rassenti et al., 2000b, and Offerman et al., 2002). Huck et al. (2001) survey previous results on experimental quantity competition with special attention to the relation between the number of firms and market outcomes. They report that with two firms there is some collusion and that with three firms market outcomes tend to be close to the one-shot Cournot equilibrium prediction.

To isolate the effect of forward markets on competition, we therefore start from a situation in which we expect little baseline collusion, i.e., we take three firms as our starting point. With respect to the number of agents in the forward market, we follow the suggestion of Allaz and Vila (1993) and introduce two traders who compete in bidding for quantities, preceding competition in the spot market. Under this Bertrand-type competition, the forward market should be expected to be sufficiently competitive.

Aside from competition with (only) three producers and competition with three producers and two traders in a forward market, we also consider the case with four producers (and no forward market). We do so for two reasons. First, these treatments provide a policy-motivated standard of comparison for the impact of a forward market, since the possibility of increasing competition through new entry or divestiture is one of the main options often mentioned in the public debate on regulatory reforms in the electricity industry. ${ }^{2}$ Second, it provides a control for the presence of a pure numbers effect. Given the way in which we represent the forward market, the number of active participants in the subsequent spot market will be equal to the number of producing firms plus, possibly, a trader who is active in the spot market. If behavior were driven purely by the number of active agents then adding a forward market would lead, in principle, to the same outcome as adding one more competitor. By obtaining information on the case with four producers we will be able to control for this effect.

Finally, we need to make some choices on the cost and demand conditions. Our main point of interest is in the behavior of producers in distinct environments. As in most experiments in this field ( $c f$. Huck et al., 2001), we therefore simulate the demand side of the market and simplify the situation considerably by assuming linearity. On the producers' side we wish marginal costs to exhibit some convexity and, therefore, we use a quadratic marginal cost schedule. Green and Newbery (1992) model high end marginal cost as quadratic. Borenstein, Bushnell and Wolak (2002) present data-based marginal cost schedules that exhibit the "hockey-stick" shape at high quantity levels, which we attempt to approximate with our design choice.

Throughout we choose to implement a complete information environment where all participants know the demand and cost functions and the latter is common to all producers. This simplification allows us to focus on the main issues we are interested in. The theoretical models we will relate our

\footnotetext{
${ }^{2}$ Newbery (forthcoming) refers to sufficient capacity as one of the necessary ingredients of well-functioning electricity markets.
} 
experiments to also assume complete information. A priori it is not clear that incomplete information would have differential effects across our treatments, so that it should not be expected to affect our comparative results.

Summarizing, our experiments use a stylized representation of electricity markets with quadratic marginal cost functions and (simulated) linear demand. Table 1 gives an overview of the treatments discussed above.

\begin{tabular}{|lccc|}
\hline \multicolumn{4}{c|}{ Table 1: Summary of the Treatments } \\
\hline & \multicolumn{2}{c|}{ Only Spot Market } & $\begin{array}{c}\text { Spot Market and } \\
\text { Forward Market }\end{array}$ \\
Quantity competition & C3.0: 3 producers & C4.0: 4 producers & C3.2: 3 producers \\
(Cournot) & 0 traders & 0 traders & 2 traders \\
Supply Function & SF3.0: 3 producers & SF4.0: 4 producers & SF3.2: 3 producers \\
Competition & 0 traders & 0 traders & 2 traders \\
\hline
\end{tabular}

The treatments called $\mathrm{C}$ (ournot)3.0 and $\mathrm{S}$ (upply)F(unction)3.0 are our benchmark spot market treatments with 3 producing firms and, due to the absence of a contract market, 0 traders. C3.2 and SF3.2 are treatments with a spot and a forward contract market, where the number 2 now stands for the presence of two traders. C4.0 and SF4.0 both involve only spot markets with 4 producing firms.

\section{Experimental procedures and design details}

\subsection{Procedures}

The experiments were conducted at the CREED laboratory for experimental economics of the University of Amsterdam. Subjects were recruited by public advertisement on campus and were mostly undergraduate students in economics, business and law. They were allowed to participate in only one experimental session. At the outset of each session, subjects were randomly allocated to the laboratory terminals and were asked to read the instructions displayed on their screens. ${ }^{3}$ Then they were introduced to the computer software and given five trial rounds to practice with the software's features. Subjects were told that during these trial rounds, other subjects' decisions were simulated by the computer, that is programmed to make random decisions and that gains or losses made during those rounds would not count. Once the five trial rounds were over, the pool of subjects was divided into independent groups (markets). For the triopoly (quadropoly) treatments, each of these groups was composed of 3 (4) subjects and for the triopolies-with-contracts, each group consisted of 5 subjects (3 producers and 2 traders). Three or four markets ran simultaneously in a session. Subjects stayed in the same market and same role for the whole session and did not know who of the other subjects are in

\footnotetext{
${ }^{3}$ A transcript of the instructions is included in Appendix 1.
} 
the same market as themselves. Each session consisted of 25 repetitions (rounds) and lasted for about 2 to 4 hours. One round took approximately 3-5 minutes to be completed.

Earnings in the experiment were denoted in experimental francs. We used an exchange rate of 5000 francs to 1 Dutch guilder $(\approx € 0.45)$. The average earning from participating in these experiments was $€ 24,60$. There was no show-up fee. As will become clear below, it was possible to have negative earnings in our experiments (especially for traders). For this reason we gave each trader a capital balance of 45000 francs plus an additional 2000 francs per round ${ }^{4}$ and each producer one of 5000 francs. Nevertheless, the possibility of bankruptcy remained. In the instructions, subjects were informed that if they exhausted their capital balance, they would be asked to leave the experiment without earnings. In total, we ran 12 sessions with 45 groups and bankruptcy occurred for 5 individuals. As will be explained in section 5, we will disregard from our data analysis the groups in which a bankruptcy occurred.

Subjects remain in fixed groups throughout a session. This procedure approximates best actual circumstances in most oligopolistic markets and, in particular, in the kind of electricity markets that we are interested in. It is followed in all previously cited experiments on quantity competition, as well as in many other oligopoly experiments (Holt, 1995). The procedure has also the advantage of yielding an independent observation for each of the experimental groups.

\subsection{Demand and Supply}

The demand function used is the linear function

$$
p(q)=\max \{0,2000-27 q\}, \quad q \geq 0,
$$

where $p$ denotes price and $q$ quantity. Subjects are not given this equation but can see a table on their screen (through which they can scroll) and also receive a printed version of the table on a handout. In the sessions with quantity competition, this table has two columns, giving aggregate quantities and the corresponding market price. In the supply function sessions, the table has the same two columns containing the demand information, as well as an additional column giving the aggregate supply function submitted by the producers.

The marginal cost function used ( $c f$. section 2$)$ is:

$\operatorname{mc}(q)=2 q^{2}, q \geq 0$

Production takes place in discrete units. Cumulative costs are given by: ${ }^{5}$

\footnotetext{
${ }_{5}^{4}$ As will be discussed in section 4, in equilibrium traders will have expected earnings equal to zero from the trade itself.

${ }^{5}$ Note that the total cost function in (3) is not a simple integration of (2) because only discrete levels of production are possible in the experiment. In fact, in the experiment (1) and (2) are only evaluated at integer values of $q$.
} 


$$
c(q)=2 \sum_{l=1}^{q} l^{2}
$$

These functions are also given in tabular form - both on the screen and as a handout - with columns representing the number of the unit, the marginal cost of that unit and the cumulative costs. The screen in the Cournot sessions has a fourth column, where the subject can indicate the quantity she wants to offer. In the supply function sessions the extra column is used by subjects to indicate the minimum price they require in order to produce that unit.

\subsection{Cournot treatments}

We now turn to a description of the actual decision sequences in the various treatments. In any given round $t$ of $\mathrm{C} 3.0$ and $\mathrm{C} 4.0$ each of the participants $i$ has to independently decide how many units, $q_{t i} \in \mathbb{N}$, to produce and supply to the market. Each producer has a capacity limit of 30 units, i.e., $0 \leq$ $q_{t i} \leq 30$; note that the demand at a price of zero is less than the sum of the capacities of the three producers. After producers have made their decisions the computer aggregates the units produced by the different producers in a group $\left(q_{t}=\sum_{i} q_{t i}\right)$, determines the market price, $p_{t}$, using eq. (1), and each producer's profits in round $t, \pi_{t i}$, as:

$$
\pi_{t i}=p\left(q_{t}\right) q_{t i}-c\left(q_{t i}\right), \quad t=1, \ldots, 25
$$

where $p(\cdot)$ is given in eq. (1) and $c(\cdot)$ is determined using eq. (3). The aggregate supply (and production), $q_{t}$, and corresponding market price, $p_{t}$, are highlighted on the screen in the table corresponding to the demand function. Then the next round starts. Rounds are independent of each other in the sense that supply can not be transferred across rounds.

In C3.2 each round is composed of three phases. In phase 1 the 3 producers independently post quantities $q_{t i}^{f} \in \mathbb{N}, i=1,2,3$, for sale on the forward market. These are aggregated, $\left(q_{t}^{f} \equiv \sum_{i} q_{t i}^{f}\right)$, and offered for purchase to two traders. Then the round enters phase 2 in which each trader $j$ can independently bid unit prices, $b_{t j}$, for the purchase of the total quantity offered by the producers. ${ }^{6}$ The bidder with the highest of the two bids $\left(b_{t} \equiv \max _{j}\left\{b_{t j}\right\}\right)$ obtains the total quantity offered, with a random assignment in case of a tie and no sale if both bids are 0 . Producers are then informed about

\footnotetext{
${ }^{6}$ In order to simplify their calculation of profitable bids, the bids are made as a per unit offer. The winning bidder must buy all units offered in phase 1 , however. Traders are told what the two bids were in the previous round.
} 
total forward production $\left(q_{t}^{f}\right)$, the winning bid $\left(b_{t}\right)$, and their profits from sales on the forward market ${ }^{7}$ :

$$
\pi_{t i}^{f}=b_{t} q_{t i}^{f}-c\left(q_{t i}^{f}\right), \quad t=1, \ldots, 25
$$

where $c\left(q_{t i}^{f}\right)$ is determined by the cost function (3).

The round then proceeds to phase 3 , the spot market. Now, producers decide whether and how much to produce for sale on the spot market, in addition to what they have already sold on the contract market. The trader who purchased the quantity offered on the forward market decides how much of it to offer for resale on the spot market. Then the market operates in the standard quantity competition way. The quantities (produced and) offered by the producers in the spot market, $q_{t i}^{s 1} \in \mathbb{N}\left(\leq 30-q_{t i}^{f}\right)$ and the quantity offered by the trader, $q_{t}^{s 2} \in \mathbb{N}\left(\leq q_{t}^{f}\right)$, are aggregated to obtain the total quantity supplied on the spot market $\left(q_{t}^{s} \equiv \sum_{i} q_{t i}^{s 1}+q_{t}^{s 2}\right)$. The spot market price is determined by $q_{t}^{s}$ and the demand function in eq. (1). The producers are then informed of their profit from spot market sales, $\pi_{t i}^{s 1}$, and the active trader of his overall profits, $\pi_{t}^{s 2}$. These are given by:

$$
\begin{aligned}
& \pi_{t i}^{s 1}=p_{t}\left(q_{t}^{s}\right) q_{t i}^{s 1}-2 \sum_{l=q_{t i}^{f}+1}^{q_{t i}} l^{2}, \quad t=1, \ldots, 25 \\
& \pi_{t i}^{s 2}=p_{t}\left(q_{t}^{s}\right) q_{t i}^{s 2}-b_{t} q_{t}^{f}, \quad t=1, \ldots, 25
\end{aligned}
$$

where $q_{t i}$ now denotes the total quantity produced by producer $i\left(=q_{t i}^{f}+q_{t i}^{s 1}\right)$. Contrary to the case without traders (eq. 4), the quantity produced need not be equal to the quantity sold to consumers on the spot market. Technically, the winning trader may choose to withhold units bought in the forward market from the spot market, so that $\sum_{i} q_{t i} \equiv q_{t}=q_{t}^{f}+\sum_{i} q_{t i}^{s 1} \geq q_{t}^{s 2}+\sum_{i} q_{t i}^{s 1} \equiv q_{t}^{s} .8$

Eq. (6) shows that the costs of producing units for the spot market depend on the quantity produced for the forward market. This is important because of the quadratic form of the marginal cost function (2). Furthermore, eq. (7) shows that traders must pay for all units bought in the forward market, even if they do not sell them all (i.e., even if $q_{t}^{s 2}<q_{t}^{f}$ ).

\footnotetext{
${ }^{7}$ From a conceptual point of view the fact that producers are informed about forward positions is an important procedural detail. In their theoretical analysis, Hughes and Kao (1997) show that if the hedging motive is not present (as in our experiments) then the unobservability of forward positions makes the strategic effect of forward markets disappear. We chose to implement the case of observability because our interest here is in giving the efficiency-promoting effects of forward markets its best shot; the specific issue of the impact of observability could be studied in future work.

${ }^{8}$ As will be shown below, the fact that traders could choose not to resell units has no practical importance in our experiments, since typically all units were resold by traders.
} 
Finally, the aggregate supply in the spot market, $q_{t}^{s}$, and the corresponding market price, $p_{t}$, are highlighted on the screen in the table corresponding to the demand function. Then the next round starts. Rounds are independent, neither producers nor traders can transfer supply across rounds. The way in which total profits in round $t$ are calculated depends on the role of the participant. For producers $I$ :

$$
\pi_{t i}=\pi_{t i}^{f}+\pi_{t i}^{s 1}, \quad i=1,2,3, t=1, \ldots, 25
$$

For traders $\mathrm{j}$ :

$$
\pi_{t j}=d_{t j} \pi_{t j}^{s 2}, \quad i=1,2, t=1, \ldots, 25
$$

where $d_{t j}=1$ if $j$ is the winning bidder in phase 2 of round $t$ (i.e., the one that has won the contracts), and $d_{t j}=0$, otherwise.

Table 2 summarizes the symbols used to describe the production and trading side of the market. Note that total supply by producers and traders is not applicable because there is overlap where forward supply by producers is offered on the spot market by traders.

\begin{tabular}{|l|cccc|}
\hline \multicolumn{5}{|c|}{ Table 2: Symbols used for Production and Trader Quantities } \\
\hline & producer $\boldsymbol{i}$ & All producers & Traders & total \\
\hline Forward market supply & $q_{t i}^{f}$ & $q_{t}^{f}$ & 0 & $q_{t}^{f}$ \\
Spot market supply & $q_{t i}^{s 1}$ & $q_{t}^{s 1}$ & $q_{t}^{s 2}$ & $q_{t}^{s}$ \\
Total supply & $q_{t i}$ & $q_{t}$ & $q_{t}^{s 2}$ & not applicable \\
Total production & $q_{t i}$ & $q_{t}$ & 0 & $q_{t}$ \\
\hline
\end{tabular}

\subsection{Supply function treatments}

We now move to the supply function treatments. In each round of the SF3.0 and SF4.0 treatments each producer has the opportunity of offering up to 30 units of production at possibly distinct prices. Denote the vector of submitted minimum prices (i.e., the individual supply function) by $S_{t i} \equiv\left(s_{t i 1}, \ldots, s_{t i 30}\right)$, using the convention that $s_{t i 1} \equiv \infty$, if unit 1 is not offered at any price in round $t$. Individual supply functions are subject to the restriction $l>k \Rightarrow s_{t i l} \geq s_{t i k}$, i.e. higher cost units may not be offered at lower prices than lower cost units. 
After each of the producers has submitted $S_{t i}$, the computer aggregates these individual supply functions to a market supply function, denoted by $S_{t}^{m} \equiv\left(s_{t 1}^{m}, \ldots, s_{t(30 n)}^{m}\right)$, by ordering all offers $s_{t i l}$, $i=1, \ldots, n, 1=1, \ldots, 30$, in period $t$ from smaller to larger; $n$ denotes the number of producers in the market. ${ }^{9}$ Then, the computer determines the quantity produced (and sold) as the highest quantity for which the price consumers are willing to pay (eq. 1) exceeds the price that the producers wish to receive. Formally, the (integer) quantity $q_{t}$ sold in period $t$ is found by solving: ${ }^{10}$

$$
q_{t}=\left\{\max q \in \mathbb{N} \mid \max \{2000-27 q, 0\} \geq s_{t q_{t}}^{m}\right\}, \quad q=1, \ldots, 30 n
$$

This implies that $q_{t}>75$, only if $s_{t q_{t}}^{m}=0, q<q_{t}$, i.e., such large quantities will only be produced (and sold) if a large number of zeros are included in the supply functions.

Next the transaction price is determined. It is the same for all units sold. In principle, any price $p_{t} \in\left[s_{t q_{t}}^{m}, s_{t\left(q_{t}+1\right)}^{m}\right)$ will yield quantity supplied $q_{t}$. The division of surplus between consumers and producers varies in this interval. We chose to have prices determined by the demand side. Hence:

$$
p_{t}=p\left(q_{t}\right)
$$

where $q_{t}$ is determined by eq. (10) and $\mathrm{p}(\cdot)$ by eq. (1). By eq. (10), producers are willing to sell the $q_{t}^{t h}$ unit. They might also be willing to sell the $q_{t+1}^{s t}$ unit, but that would decrease the price on the demand side. This is carefully explained to the subjects in the instructions. In case all bids are accepted the price is set equal to the maximum amount the demand was willing to pay at the total quantity supplied.

After $q_{t}$ has been determined, the individual quantities produced (and sold), $q_{t i}$, are determined by counting the number of the first $q_{t}$ elements of $S_{t}^{m}$ that were taken from the individual supply functions $S_{t i}$. An individual producer's profit is then determined in the same way as in the Cournot case (eq. 4).

SF3.2 is the most complex treatment. Each round involves three phases, the first two being identical to those in the $\mathrm{C} 3.2$ treatment: producers post quantities on the contract market with the total quantity offered being purchased by the highest-bidding trader. Producers' profits in the forward market are given in eq. (5). In phase 3 producers can offer additional units for sale on the spot market

\footnotetext{
${ }^{9}$ In case of a tie the order is determined randomly.

${ }^{10}$ Note that the symbol $q_{t}^{s}$ was used in the Cournot markets to denote supply on the spot market. In a Cournot market, total supply is equal to the quantity sold, however, which is what it denotes here.
} 
using a supply function as described above for the treatments without forward market (SF 3.0 and SF 4.0). The winning trader has the opportunity of offering the purchased quantity for sale on the spot market, also using a supply function. ${ }^{11}$ The aggregate market supply function is now represented by $S_{\mathrm{t}}^{\mathrm{m}} \equiv\left(s_{t 1}^{m}, \ldots, s_{t 90}^{m}\right)$, which is the composition of the individual supply functions submitted by the three producers and the winning trader. The total transaction quantity and price are then determined in the same way as for SF3.0 and SF4.0 (eqs. 10 and 11), with $q_{t}^{s}$ replacing $q_{t}$ to denote that we are dealing with the spot market. Subjects' earnings (profits) are then calculated as in eqs. (6)-(9).

After each round subjects are informed about the total quantities produced by each of the producers. To hold the information feedback constant across treatments subjects in supply function sessions are not informed about others' bid functions but only about the quantities they traded.

\section{Theoretical predictions and hypotheses}

Table 3 reports three possible predictions for key variables that will be used as benchmarks in our analysis. These are the production levels that give the producers' joint profit maximization (JPM), the Nash equilibria (NE) for the Cournot cases and the Walras market equilibrium (W).

Table 3: Benchmarks ${ }^{\mathrm{a}}$

\begin{tabular}{cccccccc}
\hline & $\begin{array}{c}\text { JPM } \\
(\mathbf{n = 3})\end{array}$ & $\begin{array}{c}\text { JPM } \\
(\mathbf{n = 4})\end{array}$ & $\begin{array}{c}\mathbf{C E} \\
\mathbf{C 3 . 0}\end{array}$ & $\begin{array}{c}\mathbf{N E} \\
\mathbf{C 3 . 2}\end{array}$ & $\begin{array}{c}\mathbf{C E} \\
\mathbf{C 4 . 0}\end{array}$ & $\begin{array}{c}\text { Walras } \\
(\mathbf{n = 3})\end{array}$ & $\begin{array}{c}\text { Walras } \\
(\mathbf{n = 4})\end{array}$ \\
\hline$q_{t i}^{f}$ & --- & --- & --- & 6 & --- & --- & --- \\
$q_{t i}$ & 11 & 9 & $14 / 15^{\mathrm{b}}$ & $15 / 16^{\mathrm{c}}$ & $12 / 13^{\mathrm{d}}$ & 17 & 14 \\
$q_{t}$ & 33 & 36 & 43 & 45 & 49 & 51 & 56 \\
$p_{t}$ & 1109 & 1028 & 866 & 785 & 704 & 623 & 488 \\
Prod.S. & 33561 & 34728 & 29537 & 27885 & 27638 & 21063 & 19208 \\
Cons.S. & 14256 & 17010 & 24381 & 26730 & 31752 & 34425 & 41580 \\
Total $S$. & 47817 & 51738 & 53918 & 54615 & 59390 & 55488 & 60788 \\
Eff. $(\%)$ & 86.2 & 85.1 & 97.2 & 98.4 & 97.7 & 100 & 100 \\
\hline
\end{tabular}

${ }^{\mathrm{a}} q_{t i}^{f}=$ forward production by producer $i ; \quad q_{t i}=$ total quantity produced by producer $i ; q_{t}=$ total quantity produced in the market; $p_{t}=$ transaction price; Prod.S. $=$ total producer surplus (trader surplus is equal to 0); Cons.S. = consumer surplus; Total $S .=$ total surplus; Eff.= efficiency (as \% of Walrasian Surplus).

${ }^{\mathrm{b}}$ Any distribution where one producer produces 15 and two produce 14 units each.

${ }^{c}$ Once the spot market is reached, the winning trader sells all 18 units, and each of the three producers produces 9 additional units with probability .944343 and 10 units with probability .055657 , so that $q_{\mathrm{t}}=$ 45.056. See Appendix 2 for details.

${ }^{\mathrm{d}}$ Any distribution where one producer produces 13 and three produce 12 units each.

\footnotetext{
${ }^{11}$ This feature of our design may be a bit far from the way in which actual contract markets work. However, it allows us to keep analogous mechanics to those of the quantity competition case where traders post quantities on the spot market just like producers do.
} 
The JPM and W predictions in table 3 are derived straightforwardly from the demand and supply functions in eq. (1) and (2), adjusting for the fact that only discrete production levels are possible. The derivation of the Cournot equilibria are standard, the Nash equilibrium with forward trading is based on Allaz en Vila (1993). Details are given in Appendix 2.

A few things can be noted from table 2. First of all, the Walras equilibrium varies with $\mathrm{n}$ due to the increasing marginal cost schedule. Second, a forward market boosts output and surplus less than the entry of an additional producer does, though it does give higher efficiency (due to the lower surplus in the Walras equilibrium). Finally, the gain in total surplus when comparing three producers with a forward market to four traders without one, is shared between producers and consumers, though the producer surplus is shared by four instead of three producers.

Some things are not dealt with in table 3. Most importantly, we are not able to derive Nash equilibria for the supply function cases as implemented in our experiments, so that we cannot compare production and efficiency in the quantity versus supply function treatments. However, for a variety of special cases, the literature finds that, ceteris paribus, supply function competition yields higher production levels and higher efficiency than Cournot competition (e.g., Klemperer and Meyer, 1989; Bolle, 1993). Moreover, under restrictive assumptions, Green (1999) shows that with supply functions, forward markets are more efficient than spot markets alone (but still not 100\% efficient).

These observations lead to the following hypotheses about the ordering of produced quantities. ${ }^{12}$

HYPOTHESIS q.1 [based on the theoretical predictions in table 3]. In the Cournot treatments, production is highest in the case with no forward market and 4 producers and lowest with no forward market and 3 producers. Formally:

$$
q(\mathrm{C} 4.0)>q(\mathrm{C} 3.2)>q(\mathrm{C} 3.0)
$$

HYPOTHESIS $\boldsymbol{q . 2}$ [based on a conjectured extrapolation of the Green (1999)]. In the supply function treatments, production is higher with a forward market:

$$
q(\mathrm{SF} 3.2)>q(\mathrm{SF} 3.0)
$$

HYPOTHESIS $\boldsymbol{q} . \mathbf{3}$ [based on a conjectured extrapolation of theoretical results in i.a., Klemperer and Meyer, 1989; Bolle, 1993]. Production is higher with supply function competition than with Cournot competition within the same market structure. Formally:

\footnotetext{
${ }^{12}$ For notational convenience, we drop the subscript $t$ indicating the round.
} 


$$
q(\mathrm{SF} 4.0)>q(\mathrm{C} 4.0) ; q(\mathrm{SF} 3.2)>q(\mathrm{C} 3.2) ; q(\mathrm{SF} 3.0)>q(\mathrm{C} 3.0)
$$

For an analysis of efficiency, first consider the situation without a forward market. Total surplus $\sigma_{q}$ at production level $q$ (and corresponding price $p$ ) can be calculated as the sum of consumer $\left(\gamma_{q}\right)$ and producer surplus $\left(\rho_{q}\right)$ :

$$
\begin{aligned}
& \gamma_{q}=\sum_{l=1}^{q}(2000-27 l-p) \\
& \rho_{q}=p q-2 \sum_{i} \sum_{l=1}^{q_{i}} l^{2} \\
& \sigma_{q}=\gamma_{q}+\rho_{q}
\end{aligned}
$$

Denoting surplus at the Walras equilibrium by $\sigma_{\mathrm{w}}$, the efficiency at production level $q$ is given by:

$$
\Omega_{q} \equiv \sigma_{q} / \sigma_{w}
$$

From (12b) it follows that realized efficiency not only depends on the level of production, but also on the distribution of production across producers. Aside from the traditional allocative efficiency, a second type of inefficiency can occur in this environment. Because we have quadratic marginal cost functions, production inefficiency will occur if production is not split equally across producers. For any total production level $q$, define the 'equal split' distributions $Q_{q}^{e} \equiv\left(q_{1}^{e}, \ldots, q_{n}^{e}\right)$ as the production levels $q_{i}^{e}$ that fulfill:

$$
\begin{aligned}
& q_{i}^{e} \in \mathbb{N}, \\
& \sum_{i} q_{i}^{e}=q, \\
& \left|q_{i}^{e}-q_{j}^{e}\right| \in\{0,1\}, \quad i \neq j
\end{aligned}
$$


i.e., $q$ is split as equally as possible across producers. Now, we compare producer surplus in the observed distribution of $q$ across producers, $Q_{q}^{o} \equiv\left(q_{1}^{0}, \ldots, q_{n}^{0}\right)$ to that in $Q_{q}^{e}$. Production efficiency at $Q_{\mathrm{q}}^{\mathrm{o}}$ is defined as: ${ }^{13}$

$$
\Phi_{q}^{0} \equiv \rho_{q}^{0} / \rho_{q}^{e}
$$

where superscript 'o' ('e') indicates that the variable is evaluated at $Q_{q}^{o}\left(Q_{q}^{e}\right)$ and $\rho_{q}^{0} \leq \rho_{q}^{e}$. Note that the interpretation of $\Phi_{q}^{0}$ as an efficiency measure is not straightforward if $\rho_{q}^{0}<0$ (or even $\rho_{q}^{e}<0$ ). In that case producers are making a loss (even if producing efficiently). Because our data only have 7 cases with $\rho_{q}^{0}<0$ (5 of which also have $\rho_{q}^{e}<0$ ), we maintain the interpretation of $\Phi_{q}^{0}$ as an efficiency measure.

For the inefficiency at $Q_{q}^{o}, 1-\Omega_{q}^{0}$, it easily follows from eqs. (12)-(15) that: ${ }^{14}$

$$
1-\Omega_{q}^{0}=\frac{1}{\sigma_{w}}\left\{\left(\gamma_{w}-\gamma_{q}\right)+\left(\rho_{w}-\rho_{q}^{e}\right)+\left(1-\Phi_{q}^{0}\right) \rho_{q}^{e}\right\}
$$

Eq. (16) shows that there are three possible sources of inefficiency. The first term in brackets reflects the loss in consumer surplus due to an inefficient production level. The second term gives the loss in producer surplus due to an inefficient level of production, (hypothetically) assuming this level is produced efficiently. ${ }^{15}$ The third term in brackets describes the efficiency loss caused by production inefficiency.

Next consider the situation with a forward market. Note that no surplus is created by traders. They do not produce, nor consume anything. In the forward market, they can attempt to obtain some of the surplus created by producers, however. As shown by Allaz and Vila (1993), their profit is zero in equilibrium. The intuition is that the two traders are bidding in a common value auction with (in equilibrium) certainty about the value of the units they buy and will therefore bid the value. In practice, traders can cause a redistribution or a decrease in realized total surplus. The surplus that producers and traders realize, depends on the quantities in the two markets and is denoted by $\hat{\rho}_{q^{f}, q^{s 1}}$

\footnotetext{
${ }^{13}$ Because it makes a difference how production is distributed across producers, from here onward, the subscript to the efficiency symbols will refer to the distribution (automatically implying the quantity as well).

${ }^{14} \mathrm{We}$ assume that production is efficient in the Walras equilibrium.

${ }^{15}$ Note that, typically, $\left(\rho_{w}-\rho^{e}\right)<0$, i.e., producers gain from restricting production below Walras. Sometimes, $\rho^{e}<\rho^{w}$ or even $\rho^{e}<0$ because producers are restricting production too much or producing more than the Walras quantity.
} 
and $\tau_{q^{f}, q^{s 2}}$, respectively. Consumer surplus is created by the total quantity supplied to the spot market, $q^{s}$, which is not necessarily equal to the quantity produced, $q\left(=q^{f}+q^{s 1}\right)$. We now have the following surplus for consumers, producers and traders:

$$
\begin{aligned}
& \gamma_{q^{s}}=\sum_{l=1}^{q^{s}}(2000-27 l-p) \\
& \hat{\rho}_{q^{f}, q^{s 1}}=b q^{f}+p q^{s 1}-2 \sum_{i} \sum_{l=1}^{q_{i}} l^{2}, \\
& \tau_{q^{f}, q^{s 2}}=p q^{s 2}-b q^{f}
\end{aligned}
$$

Which gives total surplus:

$$
\sigma^{0}=\gamma_{q^{s}}+\hat{\rho}_{q^{f}, q^{s 1}}+\tau_{q^{f}, q^{s 2}}
$$

Note that for $q^{s 2}=q^{f}$, it follows that $\hat{\rho}_{q^{f}, q^{s 1}}+\tau_{q^{f}, q^{s 2}}$ reduces to:

$$
(\hat{\rho}+\tau)_{q^{s}}=p q^{s}-2 \sum_{i} \sum_{l=1}^{q_{i}} l^{2}=\rho_{q^{s}},
$$

where $\rho_{q^{s}}$ is given in eq. (12b). In other words, if traders resell everything, then for any production level $q$ (with corresponding market price $p$ ), a sale of $q^{f}$ on the forward market at price $b$ will yield a redistribution of surplus (as defined in 12b) from producers to traders of $(p-b) q^{f}$ without affecting the aggregate surplus on the supply side of the market. Hence, for efficiency it does not matter how much is sold via the forward market, as long as traders sell everything on the spot market: $q^{s 2}=q^{f}$.

A decrease in realized surplus will occur, if traders do not resell on the spot market all goods they buy on the forward market. Consider production level $q\left(=\sum_{i} q_{i}\right)$, forward production quantity $q^{f}$, and spot market quantity $q^{s}\left(=q^{s 1}+q^{s 2}\right)$. By comparing the surplus at observed production $Q_{q}^{o}$ to the surplus at the Walras production level (with all forward trades resold on the spot market), we obtain: 


$$
\begin{aligned}
1-\Omega_{q}^{0}= & \frac{1}{\sigma_{w}}\left\{\left(\gamma_{w}-\gamma_{q^{s}}\right)+\left(\rho_{w}-\hat{\rho}_{q^{f}, q^{s 1}}-\tau_{q^{f}, q^{s 2}}\right\}=\right. \\
& \frac{1}{\sigma_{w}}\left\{\left(\gamma_{w}-\gamma_{q^{s}}\right)+\left(\gamma_{q}-\gamma_{q^{s}}\right)+\left(\rho_{w}-\rho_{q}\right)+p(q) q-p\left(q^{s}\right) q^{s}\right\}= \\
& \frac{1}{\sigma_{w}}\left\{\left(\gamma_{w}-\gamma_{q^{s}}\right)+\left(\gamma_{q}-\gamma_{q^{s}}\right)+\left(\rho_{w}-\rho_{q}^{e}\right)+\left(1-\Phi_{q}^{0}\right) \rho_{q}^{e}+p(q) q-p\left(q^{s}\right) q^{s}\right\}=
\end{aligned}
$$

Eq. (19) shows that there are five possible sources of inefficiencies in case of forward markets. As before, the first term gives the consumer surplus lost due to an inefficient level of production. The second term adds to this loss in consumer surplus if traders do not resell all units. The third term is negative and reflects the gain of producer surplus which would occur even if producers produce efficiently and all products are resold. The fourth term reflects production inefficiency. The final term gives the producer surplus lost or gained (at market value) because not all units produced for the forward market are resold. Note that if traders do resell all units, eq. (19) reduces to (16), because the second and fifth terms drop out.

From this analysis, we derive the following hypotheses.

HYPOTHESIS $\Omega .1$ [based on the theoretical predictions in table 3]. In the Cournot treatments, efficiency is highest in the case with forward market and lowest with no forward market and 3 producers. Using $\Omega(\mathrm{x})$ to denote efficiency in market structure $\mathrm{x}$ :

$$
\Omega(\mathrm{C} 3.2)>\Omega(\mathrm{C} 4.0)>\Omega(\mathrm{C} 3.0)
$$

HYPOTHESIS $\Omega .2$ [[based on a conjectured extrapolation of Green (1999)]. In the supply function treatments, efficiency is higher in the case with forward market:

$$
\Omega(\mathrm{SF} 3.2)>\Omega(\mathrm{SF} 3.0)
$$

HYPOTHESIS $\Omega .3$ [based on a conjectured extrapolation of theoretical results in i.a., Klemperer and Meyer, 1989; Bolle, 1993]. Efficiency is higher with supply function competition than with Cournot competition within the same market structure:

$$
\Omega(\mathrm{SF} 4.0)>\Omega(\mathrm{C} 4.0) ; \Omega(\mathrm{SF} 3.2)>\Omega(\mathrm{C} 3.2) ; \Omega(\mathrm{SF} 3.0)>\Omega(\mathrm{C} 3.0)
$$


HYPOTHESIS $\Phi .1$ [based on the idea that the likelihood of inefficiencies in production increases with the complexity of the market structure]. An increase in the number of producers or the introduction of a forward market decreases production efficiency. Using $\Phi(\mathrm{x})$ to denote production efficiency in market structure $\mathrm{x}$ :

$$
\Phi(\mathrm{C} 3.2)<\Phi(\mathrm{C} 3.0) ; \Phi(\mathrm{C} 4.0)<\Phi(\mathrm{C} 3.0) ; \Phi(\mathrm{SF} 3.2)<\Phi(\mathrm{SF} 3.0) ; \Phi(\mathrm{SF} 4.0)<\Phi(\mathrm{SF} 3.0)
$$

\section{Experimental Results}

We have complete data from seven groups of C3.0, SF3.0, C4.0 and SF4.0 and six groups of C3.2 and SF3.2; these groups are statistically independent from each other, since each individual participated in only one group. In addition, in one session of each of the C3.2, C4.0, and SF3.0 sessions and in two groups in the SF3.2 treatments a bankruptcy occurred in rounds 2, 2, 15, 1 and 5, respectively. Only in the last case was it a trader that went bankrupt, the other four participants concerned were producers. Because we have so few data from these groups, our analysis will disregard the data from all groups where a bankruptcy occurred. ${ }^{16}$ Moreover, since decision-makers in electricity markets are experienced professionals who interact with each other frequently, we are particularly interested in subjects' behavior towards the end of the experiment. Much of the analysis will therefore be based on the last ten rounds of the experiment

In section 5.1 we first present an overview of behavior across rounds and treatments. In section 5.2 we will test the hypotheses presented above. Section 5.3 considers, for treatments C3.2 and SF3.2, behavior in the contract and the spot market separately. In a final subsection, we will look more closely at the bid functions used in the SF treatments.

\subsection{Aggregate production and efficiency per treatment}

Figure 1 shows for each treatment the evolution of total quantities sold, averaged over groups. Market structure is distinguished by the markers on the lines (squares for 4.0, circles for 3.2 and triangles for 3.0). Cournot versus supply function treatments are distinguished by the filling of the markers (Cournot treatments having filled markers). Where applicable, the quantities shown in figure 1 are aggregated over forward and spot markets.

\footnotetext{
${ }^{16}$ In the $\mathrm{C} 4.0$ case, the bankruptcy transformed the group into a $\mathrm{C} 3.0$ case after round 2 . None of our conclusions change, if we add this group to the $\mathrm{C} 3.0$ data.
} 
Figure 1: Average Number of Units produced per round

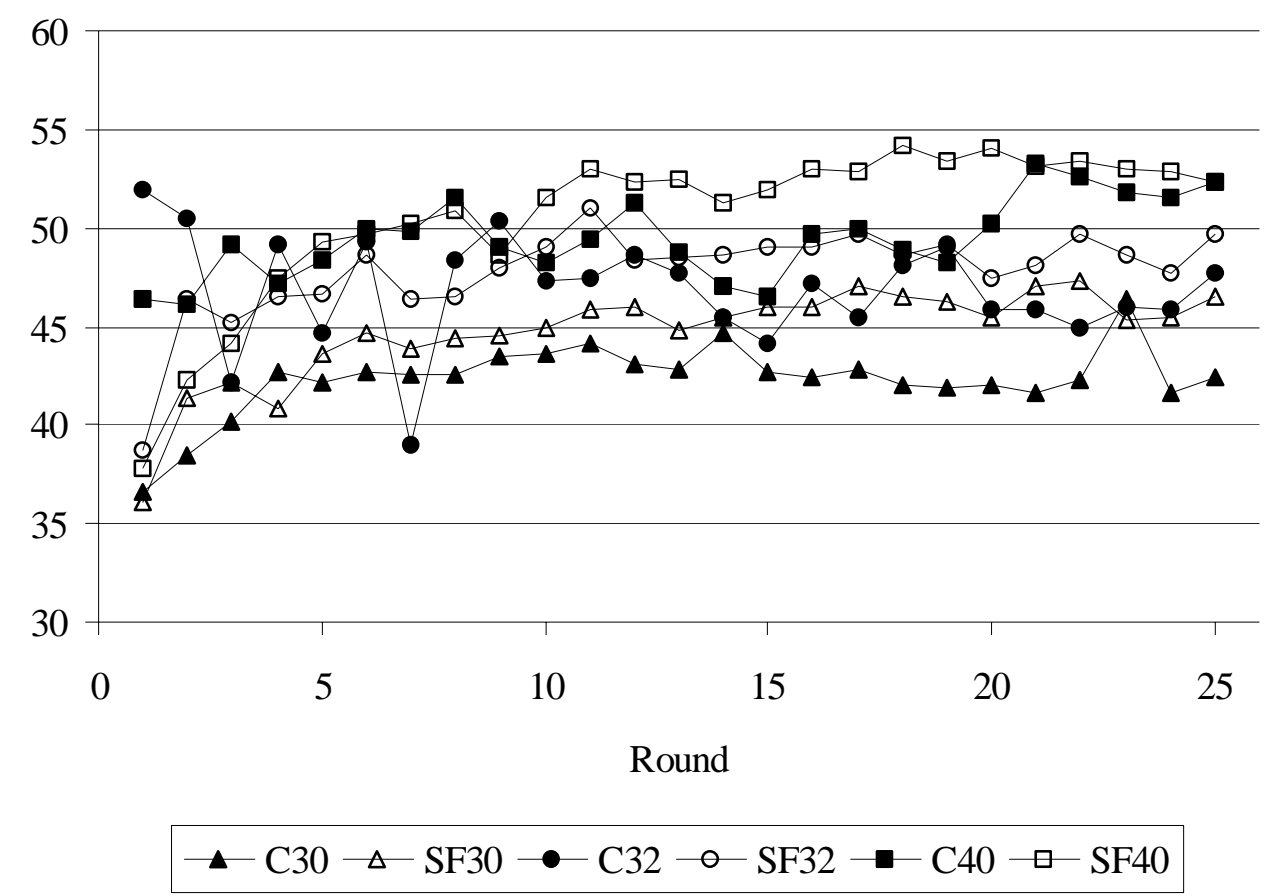

In general, we do not observe strong differences in the volatility of total quantities between early and late play. ${ }^{17}$ With respect to changes in means, there appears to be some initial upward adaptation for C3.0, SF3.0, SF3.2 and SF4.0 but not so for the other two treatments (C3.2 and C4.0). In late rounds, the highest mean quantities are observed for the two 4.0 treatments, followed by the two 3.2 treatments, with the two 3.0 treatments having the lowest means. In all cases, the SF treatment shows higher average means in late rounds than the corresponding $\mathrm{C}$ treatment. These observations are confirmed by Table 4, which reports for each group the average and standard deviations of the total quantities sold per group and treatment in the last 10 rounds, where groups are ranked from low to high mean production.

Comparing the average production levels in the Cournot treatments to the corresponding Nash equilibria in table 3 (43 for C3.0, 45 for C3.2, 49 for C4.0) we find that, in aggregate, our results for the $\mathrm{C}$ treatments correspond quite closely to the Nash predictions. We cannot reject (at $\alpha=.10$, binomial test) the null hypothesis that the difference between observed and predicted production levels is equally likely to be positive and negative.

Finally, considering the observed average production level as percentage of the Nash level, we find $99 \%, 104 \%$ and $104 \%$ for C3.0, C3.2, C4.0, respectively. This compares nicely to the $103 \%$ and $105 \%$ that Huck et al. (2001) report for similar settings (with no forward markets involved).

\footnotetext{
${ }^{17}$ In Rassenti et al. (2000) behavior under quantity competition appears to be much more volatile, even in the last 25 of their 75 rounds. Their experiments involve differences in firms' (constant) marginal costs and this may be the explanation for such volatility in their data.
} 
Table 4: Average Total Production in the last 10 rounds

\begin{tabular}{|c|c|c|c|c|c|c|}
\hline Group & C3.0 & SF3.0 & C3.2 & SF3.2 & C4.0 & SF4.0 \\
\hline \multirow[t]{2}{*}{1} & 30.7 & 38.9 & 41.8 & 44.1 & 41.5 & 50.7 \\
\hline & (2.06) & $(2.85)$ & (3.91) & $(2.38)$ & (1.96) & (1.06) \\
\hline \multirow[t]{2}{*}{2} & 42.2 & 43.9 & 44.8 & 48.3 & 47.2 & 52.0 \\
\hline & $(2.86)$ & $(.32)$ & (2.62) & $(2.36)$ & $(2.25)$ & (0) \\
\hline \multirow[t]{2}{*}{3} & 42.6 & 46.6 & 46.7 & 49.9 & 49.2 & 52.5 \\
\hline & (1.58) & (1.43) & $(2.87)$ & $(1.60)$ & $(3.55)$ & (3.10) \\
\hline \multirow[t]{2}{*}{4} & 43.7 & 47.2 & 47.6 & 50.0 & 50.3 & 52.7 \\
\hline & $(4.35)$ & (1.87) & (2.84) & (0) & (2.16) & (2.83) \\
\hline \multirow[t]{2}{*}{5} & 44.5 & 48.3 & 49.3 & 50.0 & 52.0 & 54.0 \\
\hline & (1.96) & (3.37) & (2.98) & (0) & (3.37) & (1.89) \\
\hline \multirow[t]{2}{*}{6} & 46.9 & 49.3 & 49.4 & 50.4 & 57.7 & 54.9 \\
\hline & (1.66) & $(2.11)$ & $(3.53)$ & $(1.26)$ & $(3.47)$ & $(.88)$ \\
\hline \multirow[t]{2}{*}{7} & 47.2 & 49.8 & --- & --- & 58.2 & 55.7 \\
\hline & $(8.23)$ & (1.62) & & & $(6.02)$ & $(.82)$ \\
\hline \multirow[t]{2}{*}{ Average } & 42.54 & 46.29 & 46.60 & 48.78 & 50.87 & 53.21 \\
\hline & $(5.57)$ & $(3.80)$ & $(2.91)$ & $(2.41)$ & $(5.86)$ & (1.74) \\
\hline $\begin{array}{l}\text { Average per } \\
\text { producer }\end{array}$ & 14.18 & 15.43 & 15.53 & 16.26 & 12.71 & 13.30 \\
\hline
\end{tabular}

For the SF treatments we have no theoretical predictions. In all three cases observed average production is higher than the corresponding Cournot predictions. When we compare the results in SF3.0 and SF4.0 with the Cournot equilibrium quantities, we reject the null of no difference in favor of the alternative that differences are more likely to be positive (at $\alpha=.10$, binomial test). In contrast, when there is a forward market the differences with the corresponding Cournot equilibrium, C3.2, are not significant. Finally, Table 4 also reports the average observed production per producer. With four firms per firm production is always smaller than with three firms and, hence, firms are on average operating at lower marginal costs.

Next we study the efficiency of the various treatments. Figure 2 reports the average efficiency across rounds. Treatments are distinguished in the same way as in Figure 1. Aside from one dip in round 23 for C3.0, efficiency stays above $90 \%$ in all treatments and shows remarkably little volatility in the last 15 rounds. The highest efficiency is observed for the supply function treatment with forward market (SF3.2). Moreover, efficiency in the supply function treatments and in the Cournot treatment with forward market (C3.2) appear to exceed that in the other two Cournot markets. 
Figure 2: Average Efficiency per round

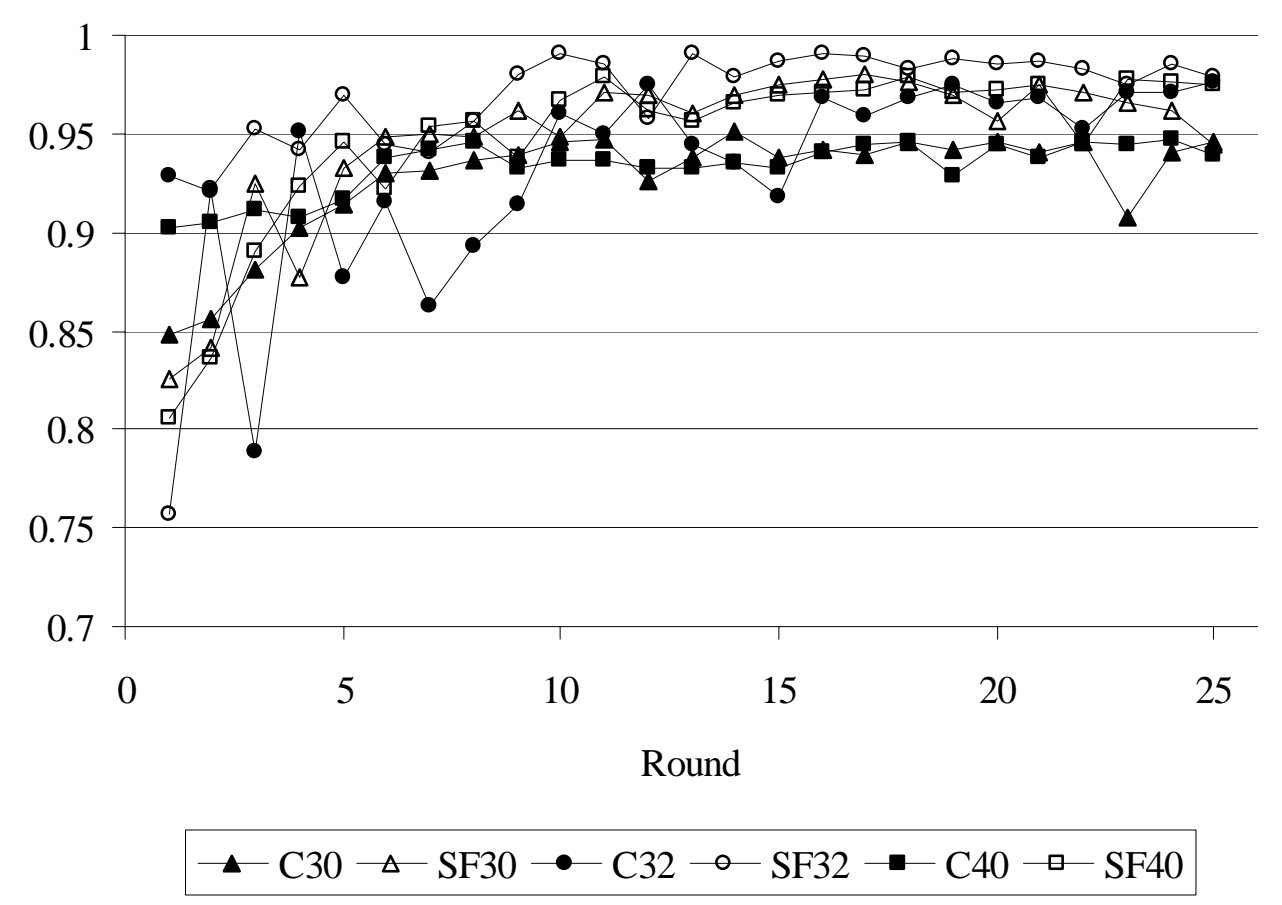

Table 5 presents the average efficiency level per group and treatment in the last 10 rounds. Groups are shown in the same order as in table $3 .{ }^{18}$ Comparing the average efficiency levels to the Nash predictions in table 3 , we find no significant difference according to the binomial test. Observed efficiency is in accordance with the theoretical prediction that efficiency is higher in the 3.2 treatments than in the 4.0 treatments, whereas production quantities are higher in the 4.0 treatments. Formal tests of these predictions are presented below. Moreover, all of the SF treatments show a higher average efficiency than all of the $\mathrm{C}$ treatments.

Finally, figure 3 gives a breakdown of the inefficiency in the last 10 rounds of each treatment, in the types distinguished in equations (16) and (19), for the sessions without, and with forward markets, respectively. Comparing the realized surplus to the surplus in the Walras equilibrium, there is a loss in consumer surplus as a consequence of reduced production and an additional loss if traders withhold units. Producer surplus is higher than at the Walras benchmark because of lower production and units withheld by traders but lower as a consequence of production inefficiency. The diamonds in figure 3 give the combined effect of all these changes in surplus.

\footnotetext{
${ }^{18}$ Given that the groups are shown in order of increasing size of production, one might expect increasing efficiency levels. There are two causes behind the non-monotonicity in the columns of table 4, however. First, production efficiency may vary across groups and cause variation in overall efficiency that is unrelated to the level of production. Second, in some rounds, some groups produce more than the Walras quantity of 51, causing a decrease in average efficiency.
} 
Table 5: Average Efficiency in the last 10 rounds

\begin{tabular}{ccccccc}
\hline Group & C3.0 & SF3.0 & C3.2 & SF3.2 & C4.0 & SF4.0 \\
\hline $\mathbf{1}$ & 79.1 & 93.1 & 93.1 & 96.1 & 87.3 & 97.0 \\
& $(2.79)$ & $(1.99)$ & $(2.50)$ & $(2.64)$ & $(1.45)$ & $(.28)$ \\
$\mathbf{2}$ & 96.1 & 93.8 & 94.0 & 96.5 & 96.2 & 95.4 \\
& $(2.88)$ & $(1.31)$ & $(3.85)$ & $(2.46)$ & $(1.39)$ & $(.32)$ \\
$\mathbf{3}$ & 96.7 & 97.9 & 97.8 & 99.3 & 96.7 & 97.4 \\
& $(1.02)$ & $(.94)$ & $(1.55)$ & $(.88)$ & $(1.59)$ & $(1.70)$ \\
$\mathbf{4}$ & 96.0 & 99.0 & 98.6 & 99.8 & 96.4 & 97.4 \\
& $(2.56)$ & $(.69)$ & $(1.65)$ & $(.17)$ & $(1.75)$ & $(1.14)$ \\
$\mathbf{5}$ & 97.6 & 95.6 & 98.6 & 99.5 & 97.8 & 96.0 \\
& $(.97)$ & $(8.31)$ & $(1.00)$ & $(.17)$ & $(.70)$ & $(6.72)$ \\
$\mathbf{6}$ & 97.9 & 98.8 & 98.3 & 99.5 & 98.0 & 97.5 \\
& $(.67)$ & $(1.21)$ & $(.86)$ & $(.55)$ & $(1.03)$ & $(1.74)$ \\
$\mathbf{7}$ & 95.9 & 99.1 & --- & --- & 95.4 & 99.2 \\
& $(1.22)$ & $(.65)$ & & & $(2.12)$ & $(.55)$ \\
\hline Average & 94.2 & 96.8 & 96.7 & 98.5 & 95.4 & 97.1 \\
& $(6.68)$ & $(2.57)$ & $(2.48)$ & $(1.67)$ & $(3.67)$ & $(1.20)$ \\
\hline
\end{tabular}

Note: Standard deviations in parenthesis. The average standard deviation is computed on the basis of the values of the average levels for the different groups.

To start, note that the production inefficiency (the fourth term in eq. 19) is small, compared to the loss in consumer surplus and gain in producer surplus. Apparently, even with the complication of quadratic marginal costs, our producers manage to produce fairly efficiently. Moreover, for the 3.2 treatments, the surplus effect of traders not reselling all units (the second and fifth term in eq. 19) is negligible. All in all, when focusing on efficiency effects, the main issue seems to be the direct effect on consumer and producer surplus (the first and third term in eq. 19).

An interesting aspect is the extent of redistribution from consumers to producers. This is represented by the size of the bars (from top to bottom) in figure 3. Note that there is always less of this redistribution in the supply function treatments than in the corresponding Cournot case. Moreover, for both C and SF, the lowest spread is observed for the 3.2 treatments. This indicates that both forward markets and supply functions are good ways to mitigate the transfer of surplus to producers. 
Figure 3: Average Inefficiency Breakdown in the Last 10 Rounds (in \%)

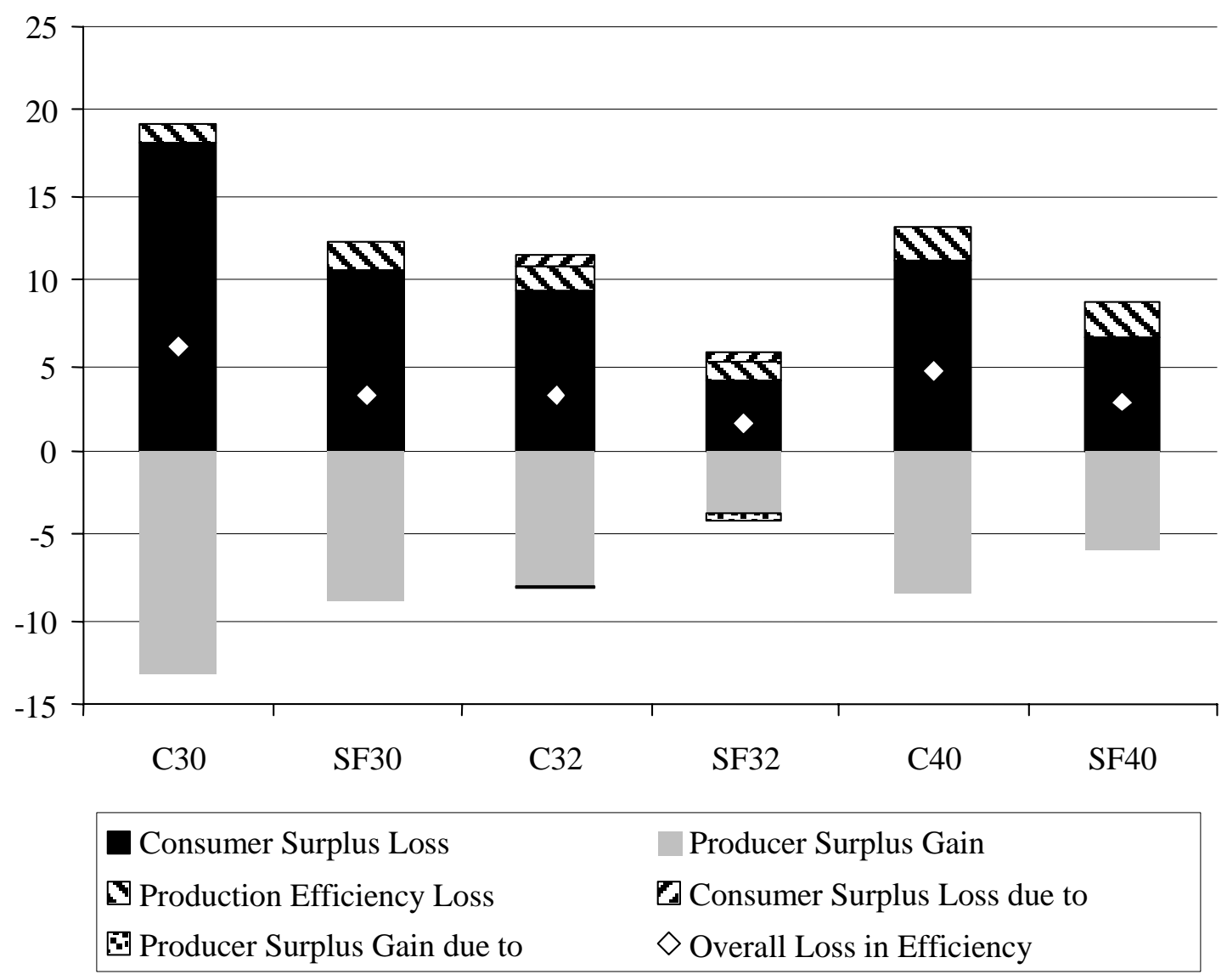

\subsection{Testing the hypotheses}

In this subsection, we present and discuss the test results for the hypotheses presented in section 4. Tests are based on the last 10 rounds of each treatment, using groups as the (statistically independent) units of observation. ${ }^{19}$ Unless indicated otherwise, we used one-tailed permutation tests to test the hypotheses. Qualitative conclusions about the rejection of hypotheses are drawn based on a 10\%significance level (with p-values given for the reader to draw conclusions for other significance levels).

\section{Hq1: $q(\mathrm{C} 4.0)>q(\mathrm{C} 3.2)>q(\mathrm{C} 3.0)$ is supported.}

- $q(\mathrm{C} 4.0)=q(\mathrm{C} 3.2)$ is rejected in favor of $q(\mathrm{C} 4.0)>q(\mathrm{C} 3.2)$; $\mathrm{p}$-value $=0.068$,

- $q(\mathrm{C} 3.2)=q(\mathrm{C} 3.0)$ is rejected in favor of $q(\mathrm{C} 3.2)>q(\mathrm{C} 3.0) ; \mathrm{p}$-value $=0.050$.

These results statistically reinforce the conclusion mentioned above that, on average, behavior conforms closely to the Nash predictions. Hence, if the quantity produced is the major variable one is interested in, then the expected effect of increased competition is larger than the effect of a forward market. This result is closely related to the convexity of the cost function. The increase in the number

\footnotetext{
${ }^{19}$ The general picture does not change if we include data from all rounds in our tests.
} 
of producers gives a higher production capacity to the industry at lower average costs. As mentioned above, many (e.g., Green, 1999) argue that the cost function in the power industry is indeed convex.

\section{Hq2: $q(\mathrm{SF3.2})>q(\mathrm{SF3.0})$ is supported.}

- $\quad q(\mathrm{SF} 3.2)=q(\mathrm{SF} 3.0)$ is rejected in favor of $q(\mathrm{SF} 3.2)>q(\mathrm{SF} 3.0)$; $\mathrm{p}$-value $=0.095$.

This result expands Green's (1999) theoretical result, which was based on specific assumptions. We can also compare SF3.2 and SF3.0 to SF4.0. Table 4 shows that average production is highest for SF4.0. This proves to be statistically significant, with p-values 0.001 and $<0.001$ for the comparison with SF3.2, SF3.0, respectively. Note that this implies a similar effect of market structure on production quantities for the supply function treatments as for Cournot competition.

\section{Hq.3: $q(\mathrm{SF3.0})>q(\mathrm{C3.0}) ; q(\mathrm{SF3.2})>q(\mathrm{C3.2}) ; q(\mathrm{SF} 4.0)>q(\mathrm{C} 4.0)$ is partially supported.}

- $q(\mathrm{SF} 3.0)=q(\mathrm{C} 3.0)$ is rejected in favor of $q(\mathrm{SF} 3.0)>q(\mathrm{C} 3.0) ; \mathrm{p}$-value $=0.084$,

- $q(\mathrm{SF} 3.2)=q(\mathrm{C} 3.2)$ is rejected in favor of $q(\mathrm{SF} 3.2)>q(\mathrm{C} 3.2) ; \mathrm{p}$-value $=0.095$,

- $\quad q(\mathrm{SF} 4.0)=q(\mathrm{C} 4.0)$ is not rejected in favor of $q(\mathrm{SF} 4.0)>q(\mathrm{C} 4.0) ; \mathrm{p}$-value $=0.174$.

This shows that supply function competition, in general, leads to higher production levels than quantity competition with the same market structure.

\section{H $\Omega .1: \Omega(C 3.2)>\Omega(C 4.0)>\Omega(C 3.0)$ is not supported.}

- $\Omega(\mathrm{C} 3.2)=\Omega(\mathrm{C} 4.0)$ is not rejected in favor of $\Omega(\mathrm{C} 3.2)>\Omega(\mathrm{C} 4.0)$; $\mathrm{p}$-value $=0.253$,

- $\Omega(\mathrm{C} 4.0)=\Omega(\mathrm{C} 3.0)$ is $n o t$ rejected in favor of $\Omega(\mathrm{C} 4.0)>\Omega(\mathrm{C} 3.0)$; $\mathrm{p}$-value $=0.325$.

Note from table 5 (last row) that the numbers go in the right direction: the highest efficiency is found for C3.2 and the lowest for C3.0. The differences are not statistically significant, however. In this case, the theoretical Nash solution is not (statistically) supported.

\section{H $\Omega .2: ~ \Omega($ SF3.2) $>\Omega($ SF3.0) is supported.}

- $\quad \Omega($ SF3.2) $=\Omega$ (SF3.0) is marginally rejected in favor of $\Omega($ SF3.2) $>\Omega$ (SF3.0); -value $=0.100$.

This result supports Green's (1999) conclusion that a forward market boosts efficiency.

\section{H $\Omega .3: \Omega($ SF3.0) $>\Omega($ C3.0); $\Omega($ SF3.2) $>\Omega($ C3.2); $\Omega($ SF4.0 $>\Omega($ C4.0) is partially supported.}

- $\quad \Omega(\mathrm{SF} 3.0)=\Omega(\mathrm{C} 3.0)$ is $n o t$ rejected in favor of $\Omega(\mathrm{SF} 3.0)>\Omega(\mathrm{C} 3.0)$; $\mathrm{p}$-value $=0.190$,

- $\Omega(\mathrm{SF} 3.2)=\Omega(\mathrm{C} 3.2)$ is marginally rejected in favor of $\Omega(\mathrm{SF} 3.2)>\Omega(\mathrm{C} 3.2)$; -value $=0.100$,

- $\quad \Omega(\mathrm{SF} 4.0)=\Omega(\mathrm{C} 4.0)$ is $n o t$ rejected in favor of $\Omega(\mathrm{SF} 4.0)>\Omega(\mathrm{C} 4.0)$; $\mathrm{p}$-value $=0.124$.

Although supply function competition increases the quantity produced, it does not necessarily increase efficiency. As discussed above, there are two reasons why an increase in production does not 
necessarily imply an increase in efficiency: production inefficiency and total production above the Walras level.

HФ.1: $\Phi($ C3.2) < $\Phi($ C3.0); $\Phi($ C4.0) < $\Phi($ C3.0); $\Phi($ SF3.2) < $\Phi($ SF3.0); $\Phi($ SF4.0) < $\Phi($ SF3.0) is partially supported. $^{20}$

- $\Phi(\mathrm{C} 3.2)=\Phi(\mathrm{C} 3.0)$ is not rejected in favor of $\Phi(\mathrm{C} 3.2)<\Phi(\mathrm{C} 3.0) ; \mathrm{p}$-value $=0.194$,

- $\Phi(\mathrm{C} 4.0)=\Phi(\mathrm{C} 3.0)$ is rejected in favor of $\Phi(\mathrm{C} 4.0)<\Phi(\mathrm{C} 3.0)$; p-value = 0.047,

- $\Phi(\mathrm{SF} 3.2)=\Phi(\mathrm{SF} 3.0)$ is not rejected in favor of $\Phi(\mathrm{SF} 3.2)<\Phi(\mathrm{SF} 3.0)$; p-value = 0.871,

- $\Phi(\mathrm{SF} 4.0)=\Phi(\mathrm{SF} 3.0)$ is rejected in favor of $\Phi(\mathrm{SF} 4.0)<\Phi(\mathrm{SF} 3.0) ; \mathrm{p}$-value $=0.075$.

Given the high level of productive efficiency ( $c f$. figure 4), these results are quite remarkable. The result for the comparison between SF3.2 and SF3.0 is surprising, with higher production efficiency in case of SF3.2 than for SF3.0, 98.6 vs. 96.9, where the opposite was expected. We have no explanation for this outcome. For the other cases, our conjecture that more complex market organization will lead to higher production inefficiencies finds support.

All in all, there is quite some support for the various hypotheses, albeit more for our hypotheses on quantities than for those on efficiencies. Given that most of the hypotheses were derived from theory or conjectured extensions of theory, this result supports the existing theory on forward markets and supply function competition. Both are beneficial to the competitiveness of markets.

\subsection{Behavior on the forward market}

Next, we consider what occurs on the forward markets. We start with a comparison of production for the forward and spot markets. Figure 4 shows, for both treatments with contracts, the evolution of average individual production separately for the spot and the forward market.

\footnotetext{
${ }^{20}$ For the tests conducted here we dropped the (two) cases in the last ten rounds where $\rho_{q}^{0}<0$.
} 
C3.2

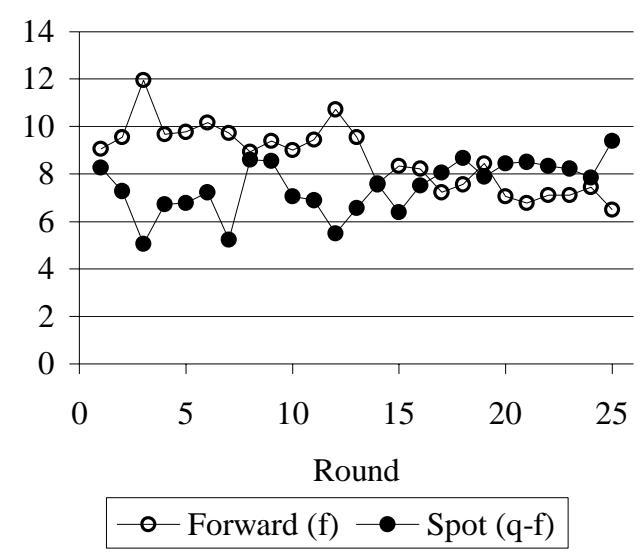

SF3.2

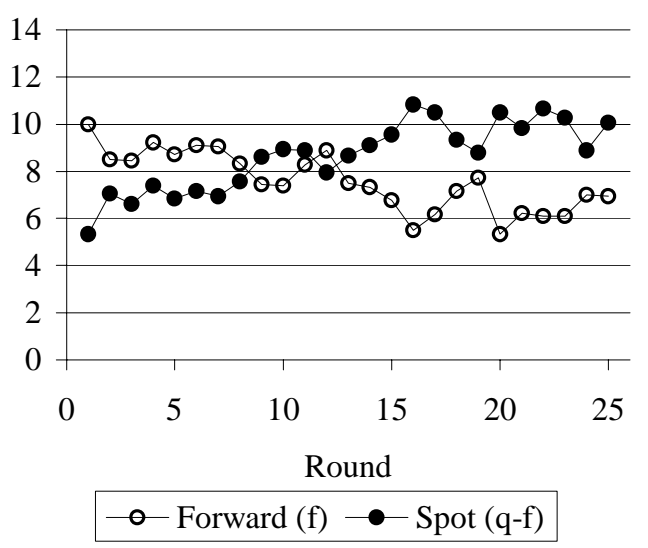

Figure 4: Average Individual Production per Round on Spot and Forward Markets

Recall from table 3 that the equilibrium prediction for the Cournot market (C3.2) is that each firm produces 6 units for the forward market and an additional quantity of either 9 or 10 units for the spot market. Figure 4 (left panel) shows that production comes quite close to this equilibrium in the last part of the experiment, with an overproduction of about one unit for the forward market. Formally the hypotheses that $q^{f}=6$ and $q^{s 1}=9-10$ are tested by checking if the differences between observed and predicted quantity for the forward or spot market are equally likely to be positive or negative. We find that for each market of each treatment, we cannot reject this hypothesis so that we cannot reject the null hypothesis that producers supplied the Nash equilibrium prediction on the forward and the spot markets (p-value > .344, binomial test).

The supply function data shown in the right panel of Figure 4 exhibit a similar pattern, with spot market output levels overtaking those of the forward market in the last ten rounds. Note that we have no theoretical prediction to compare this observed level to. The data for SF3.2 look much like those for $\mathrm{C} 3.2$, however. The main difference appears to be a slightly higher level of production for the spot market in later rounds.

Notice that for both types of competition, total output remains rather constant over time. However, in both cases producers appear to be increasingly moving away from the contract market towards the spot market and the question is why. To get further insight we now look at traders' behavior in Figure 5. 
Figure 5: Winning Bids and Profits of Traders per round

Average Winnings Bids

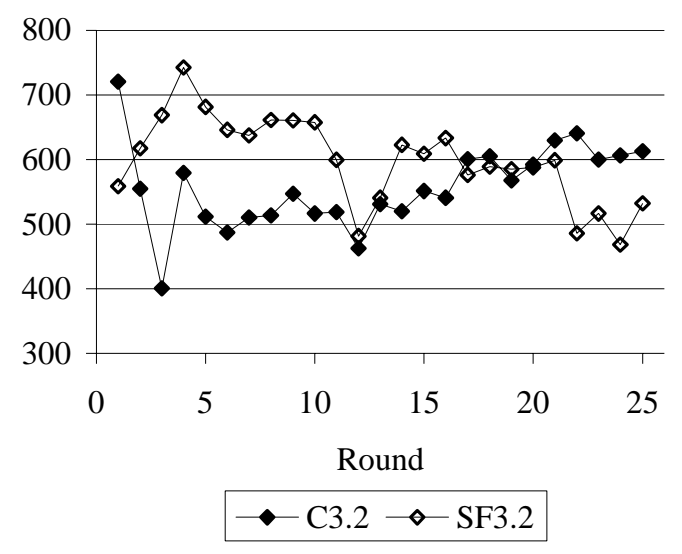

Average Profits of Traders

(in Experimental Units)

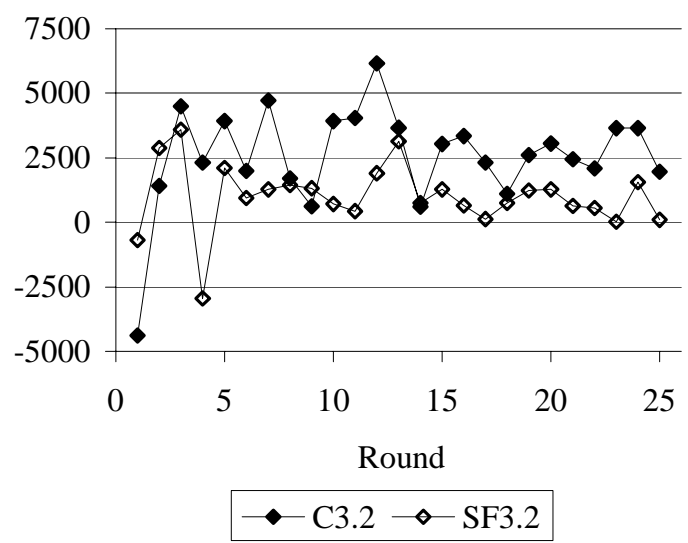

For the average winning bids, shown in the left hand panel, the equilibrium price prediction for C3.2 is 785 (see again table 1) and with respect to the right hand panel data traders are predicted to earn zero in equilibrium. As can be seen, average winning bids are below the prediction for all rounds. At the same time the right hand panel reveals that traders' profits are mostly above the equilibrium prediction of zero, although profits get close to zero in the supply function case. However, traders are typically managing to keep the prices in the forward market low enough to make a profit, and this is causing producers to offer less on these markets over time.

Comparing the Cournot markets to the Supply Function markets, we can see that the higher average production is offered on the spot market and not via the forward market (figure 4). As a consequence of the lower prices on the spot market, traders are decreasing their bids on the forward market for SF3.2. Their profits approach the equilibrium level of zero, as opposed to the profits of traders in the Cournot case. A comparison of traders' profits indicates that they are significantly greater in the Cournot markets (average: 2617) than in the supply function markets (average: 689), (pvalue $=.008)$.

These results provide insights into how forward markets work. In a sense, they are closer to the theory in the supply function case with relatively low trader profits. This goes together with relatively low prices on the forward market and high production for the spot market. In spite of the relatively low prices, the strategic incentive of forward markets works: in both treatments, producers are offering (more or less) the equilibrium quantity on these markets. This boosts total supply to levels higher than in the cases without forward markets. 


\subsection{Supply Function Behavior}

Finally, we analyze pricing behavior in the supply function treatments. The use of supply functions in an controlled environment allows us to study this behavior in more detail than has previously been done. ${ }^{21}$ There exists a simple relation to quantity competition: if all the producers and traders of a group decide to sell specific quantities at the lowest price, then the model reverts to a standard Cournot competition game, where producers only have to decide how much to produce and the market sets the price. However, most producers in our experiments preferred to compete with proper supply functions. Many traders, on the other hand, decided to offer all units at price 1 (the lowest supply price allowed). For them, this is the best guarantee to resell all units. Note that the marginal costs for supplying any unit is zero for traders. Traders realized that a supply function of ones was the best way to resell all units. They submitted these functions in more than $90 \%$ of the cases in the last 10 rounds. ${ }^{22}$ When doing so, they always sold all units.

To get a better understanding of the supply functions submitted in various treatments, we estimate aggregate supply functions across treatments using regression methods. For each group, we construct the supply function for each of the last ten rounds. These supply functions were then used to estimate an aggregate supply function for each treatment. We estimated the price for each quantity with a cubic spline (and an intercept term). Figure 6 plots the estimated supply functions. It shows that supply functions are flatter as competition increases, which confirm the previous finding that suppliers bid more competitively as competition increases. Note also that the estimated supply functions exhibit higher prices for SF3.2 than for SF4.0 at any quantity level produced.

To illustrate the difference between traders and producers, we estimated an aggregate supply function for each of them separately. The plot of the estimated function for producers lies well above that of the traders. Nevertheless, this function is relatively flat for the first forty-odd units at a price of about 500. This seems to indicate a willingness to sell these units at a constant price (below the equilibrium price) and to charge higher prices for subsequent higher cost units. The estimated supply function for traders has a flat segment at low quantities, which indicates that they want to get rid of their units. It reflects the traders offering units at price equal to 1.

\footnotetext{
${ }^{21}$ Wolak (2000) constructs a model of bidding with supply functions in an electricity market with forward hedging contracts and tests its predictions with data from the Australian electricity market. Wolfram (1998) present an empirical study of strategic bidding with supply functions in the English electricity market.

${ }^{22}$ Due to a computer bug, we have no data on the supply functions submitted in the first two SF3.2 sessions. The results reported are based on the remaining sessions.
} 
Figure 6: Estimated Aggregate Supply Functions in the last 10 rounds

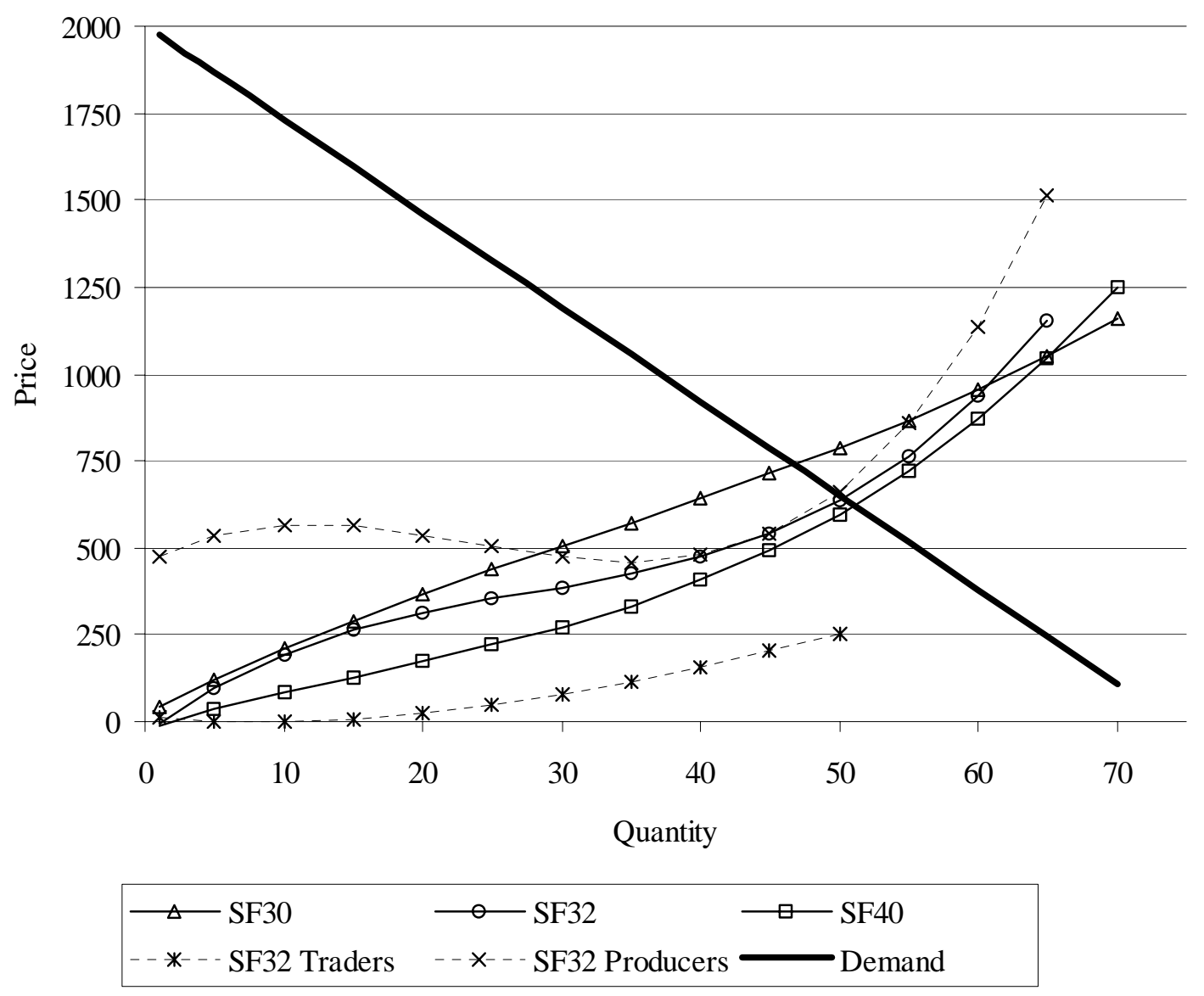

\section{Conclusion}

We find that, as the relevant theory suggests, the introduction of a forward market does have the effect of increasing total quantity produced and lowering prices paid by consumers. This result emerges from an experimental design that reflects some of the important features of actual electricity markets. Perhaps most importantly we not only study quantity competition, but also the more pertinent supply function competition. Two other central characteristics of our design are that we use increasing marginal costs to better represent production conditions in the electricity industry, and that we have a forward market with actual traders and not a purely simulated one. A final feature that we wish to highlight here is that groups remained constant during the course of our experiment. This is because the field settings that we want to represent involve repeated interactions among the same agents. All 
these features give the theory based on stage-game analysis a harder shot and yet our data are consistent with the theoretical predictions.

In fact, economic theory is consistent with the average quantity data in a number of other respects. For quantity competition - where we have a numerical stage-game prediction - we find that average behavior is remarkably close to those predictions. This is in line with evidence from other quantity competition results. However, those other studies did not consider forward markets nor increasing marginal costs, so that our evidence adds to the predictive reliability of the Cournot stagegame equilibrium in environments with repeated interaction.

For the cases with three producers with and without forward markets, prices are lower with supply function than with quantity competition. This is in accordance with the basic notion that supply functions should lead to prices in between those for price competition and quantity competition. However, for the cases with four producers and no forward market there is no significant difference between quantity and supply function competition. One may say that when there is a sufficient number of firms in the market the way in which they compete is, from the point of view of consumers, rather secondary. At the same time the shifts between the different treatments are quite alike under the two types of competition so that, to some extent, one can take quantity competition equilibria as benchmarks for supply function behavior.

From a policy perspective our main comparison is the one between adding a forward market and adding a firm. The latter alternative does lower prices more than the introduction of a forward market; in our set-up this is facilitated by our production structure, where increased capacity causes lower average costs. The data are here again quite consistent with theoretical notions. However, the result of this comparison may not be the only relevant consideration in this context. Rather, given the substantial costs of adding capacity in actual markets, the creation of a forward market may be considered to be the superior alternative. This may be reinforced by the fact that supply function competition has an additional edge in relative terms. Overall efficiency levels, i.e. realized surplus as a percentage of maximum surplus, are actually the highest with this market organization.

Our conclusions are of course conditional on a number of specific design choices. Modifications of the design, like for instance the introduction of different information conditions or of different forward market rules, may modify the results. However, we present the first experimentally controlled study combining supply functions and forward markets and for that we believe our design choices to be an appropriate baseline. Given this baseline, we consider the support our data give to the relevant theory quite remarkable. 


\section{References}

Abbink, K., J. Brandts and T.M. McDaniel (2003), "Asymmetric demand information in uniform and discriminatory call auctions: an experimental analysis motivated by electricity markets", Journal of Regulatory Economics, 23, 125-144.

Allaz B. and J.-L. Vila (1993), "Cournot competition, forward markets and efficiency", Journal of Economic Theory, 59, 1-16.

Baldrick, R., R. Grant and E. Kahn (2000), "Linear supply function equilibria: Generalizations, applications and limitations”, University of California Energy Institute POWER paper PWP-078.

Binger B.R., Hoffman E., Libecap G.D. and Shachat K.M. (1992), "An experimetric study of the Cournot model", mimeo, University of Arizona.

Bolle F. (1993), "Who Profits from Futures Markets”, Ifo-Studien 3-4, 239-256.

Bolle F. (2001), "Competition with supply and demand functions", Energy Economics, 23,253-277.

Borenstein, S. J. Bushnell and F. Wolak (2002), "Measuring Market Inefficiencies in California's Restructured Wholesale Electricity Market”, American Economic Review, 92, 5, 1376-1405

Green, R. (1999), "The Electricity Contract Market in England and Wales”, Journal of Industrial Economics, 47, 1, 107-124.

Green R. and D. Newbery (1992), "Competition in the British Electricity Spot Market", Journal of Political Economy, 100, 5, 929-953.

Hoffman, E. and C. Plott (1981), "The effect of intertemporal speculation on the outcomes in seller posted offer auction markets", Quarterly Journal of Economics, 96, 223-241.

Holt C.A. (1995), "Industrial Organization: A Survey of Laboratory Research", in The Handbook of Experimental Economics, J.H Kagel and A.E Roth (eds), Princeton University Press, 349-443.

Huck, S., H.-T. Norman and J. Oechssler (1999): "Learning in Cournot oligopoly: An experiment", Economic Journal, C80-C95. 
Huck, S., H.-T. Norman and J. Oechssler (2001): "Two are Few and Four are Many: Number Effects in Experimental Markets", mimeo, http://www.sun.rhbnc.ac.uk/ ujte171/papers.html

Hughes, J. and J. Kao (1997), "Strategic forward contracting and observability", International Journal of Industrial Organization, 16, 121-133.

Klemperer, P. and M. Meyer (1989), "Supply Function Equilibria in Oligopoly under Uncertainty", Econometrica, 57, 6, 1243-1277.

LeCoq C. and H. Orzen (2002), "Do forward markets enhance competition? Experimental evidence", SSE/EFI Working Paper \#506, University of Nottingham.

McKelvey, R., A. McLennan, and T. Turocy, 2002, "Gambit: Software Tools for Game Theory", The Gambit Project, http://econweb.tamu.edu/gambit/.

Miller, R., C. Plott and V. Smith (1977), "Intertemporal competitive equilibrium: An empirical study of speculation", Quarterly Journal of Economics, 91, 599-624.

Newbery, D. (1998), "Competition, contracts, and entry in the electricity spot market", RAND Journal of Economics, 29, 4, 726-749.

Newbery, D. (forthcoming), "Problems of liberalising the electricity industry", European Economic Review.

Offerman, T., J. Potters and J. Sonnemans (2002), "Imitation and Adaptation in an Oligopoly Experiment", Review of Economic Studies, 69, 973-997.

Rassenti S., Reynolds S.S., Smith V.L. and Szidarovszky F. (2000a), "Adaptation and convergence of behavior in repeated experimental Cournot games", Journal of Economic Behavior and Organization, 41(2), 117-146.

Rassenti, S., V. Smith and B. Wilson (2000b), "Controlling Market Power and Price Spikes in Electricity Networks: demand-side bidding”, WP, University of Arizona, December 2000.

Rassenti, S., V. Smith and B. Wilson (2001), "Discriminatory Price Auctions in Electricity Markets: Low Volatility at the Expense of High Price Levels", WP, University of Arizona, December 2001. 
Rassenti, S., V. Smith and B. Wilson (2002), "Using experiments to Inform the Privatization/Deregulation Movement in Electricity", The Cato Journal, 22, 3, winter 2002.

Rudkevich, A. (1998), "Modeling Electricity Pricing in a Deregulated Generation Industry: The Potential for Oligopoly Pricing in a Poolco", Energy Journal, 19, 3, 19-48.

Staropoli, C., D. Finon, J.-M. Glachant, C. Jullien, R. Quatrain, S. Robin and B. Ruffieux, "Modifying industry structure or market institution? An experimental analysis of the reform of the English electricity pool”, WP, University Tübingen, September 2000.

Weiss, J. (2002), “Market Power and Power Markets”, Interfaces, 32, 5, 37-46.

Williams, A. and V. Smith (1984), "Cyclical Double-Auction Markets with and without Speculators", Journal of Business, 57, 1, 1-33.

Wolak F. (2000), “An Empirical Analysis of the Impact of Hedge Contracts on Bidding Behavior in a Competitive Electricity Market", WP, Stanford University, http://www.stanford.edu/ wolak

Wolfram C.D. (1998), "Strategic bidding in a multiunit auction: an empirical analysis of bids to supply electricity in England and Wales", RAND Journal of Economics, 29(4), 703-725. 


\section{Appendix 1}

In this appendix, we give a translation of the Dutch instructions of one of our treatments: C3.2. Instructions for other treatments were similar. A full set of the (Dutch) instructions is available upon request. Instructions were computerized and programmed as linked HTML pages. Participants could move forward and backward through the instructions by simple mouse clicks. Below, horizontal lines indicate page separations.

\section{INSTRUCTIONS}

You are about to participate in an economic experiment. The instructions are simple. if you follow them carefully, you can make a substantial amount of money. Your earnings will be paid to you in guilders at the end of the experiment.

In the experiment, we use the currency 'francs'. At the end of the experiment, we will exchange the francs for guilders. The exchange rate to be used is 1 guilder for 5000 francs. For each 10000 francs, you will therefore receive 2 guilder.

We will use numerical examples in these instructions. These are only meant to be an illustration and are irrelevant for the experiment itself.

\section{ROUNDS}

The experiment will consist of 25 rounds today, preceded by 5 practice rounds.

In those rounds, you will be a member of a group. Aside from you, the group will consist of 4 other people. The composition of the group is anonymous. You do not know who is in a group with you. Others do not know that you are in their group. The composition of your group is the same for the whole experiment. You will have nothing to do with people in other groups.

In the practice rounds, there will be no groups. The computer will simulate the choices of other group members. You will therefore not be able to learn anything about the choices of others. The practice rounds are only meant to help you to learn about the problem at hand and the computer program.

In the experiment, you will participate in a market, in which fictitious goods will be produced, exchanged with traders and sold. The final consumers of the good will be simulated by the computer. Some participants today will be producers of the good, others will be traders. There are 2 traders and 3 producers in each group. At the beginning of the experiment your screen will show your type.

The remainder of these instructions will explained these roles, the market and the rules you must submit to.

\section{THREE PHASES}

Each round of today's experiment consists of 3 subsequent phases: production, trade and sales. What follows is a brief overview. Each phase is explained in more detail, below.

In phase 1 (production), all producers must make a decision. They determine how many units they would like to produce in this phase. The numbers in the group are summed up. This number is then offered for sale to the traders in the group.

In phase 2 (trade) traders must decide for what price they would be willing to buy the units offered by the producers. Each trader places a bid for these units. This bid is the price PER UNIT that the trader is willing to pay for all units offered. In this phase it is all or nothing, meaning that the trader with the highest bid obtains all units, the other trader receives nothing. If both traders bid the same amount, a lottery will decide. At the end of this phase, each producer will receive the winning bid for each unit he or she produced. 
In phase 3 (sales) the trader with the winning bid in phase 2 and the producers must make decisions. The producers can produce any units not yet produced and offer them for sale on the market. The trader can offer the units purchased on the market. What happens then, will now be explained first.

\section{THE BUYERS}

In this experiment, the decisions to buy (fictitious) goods in phase 3 are not made by participants but by the computer. This happens as follows.

In each round, the total number of units offered for sale by your group is determined. The computer then buys all of these units. The price that the computer pays depends on the number of units offered. The relationship between this number and the price is given in a table. You will see this in the upper right area of your screen. An example is given on the following page.

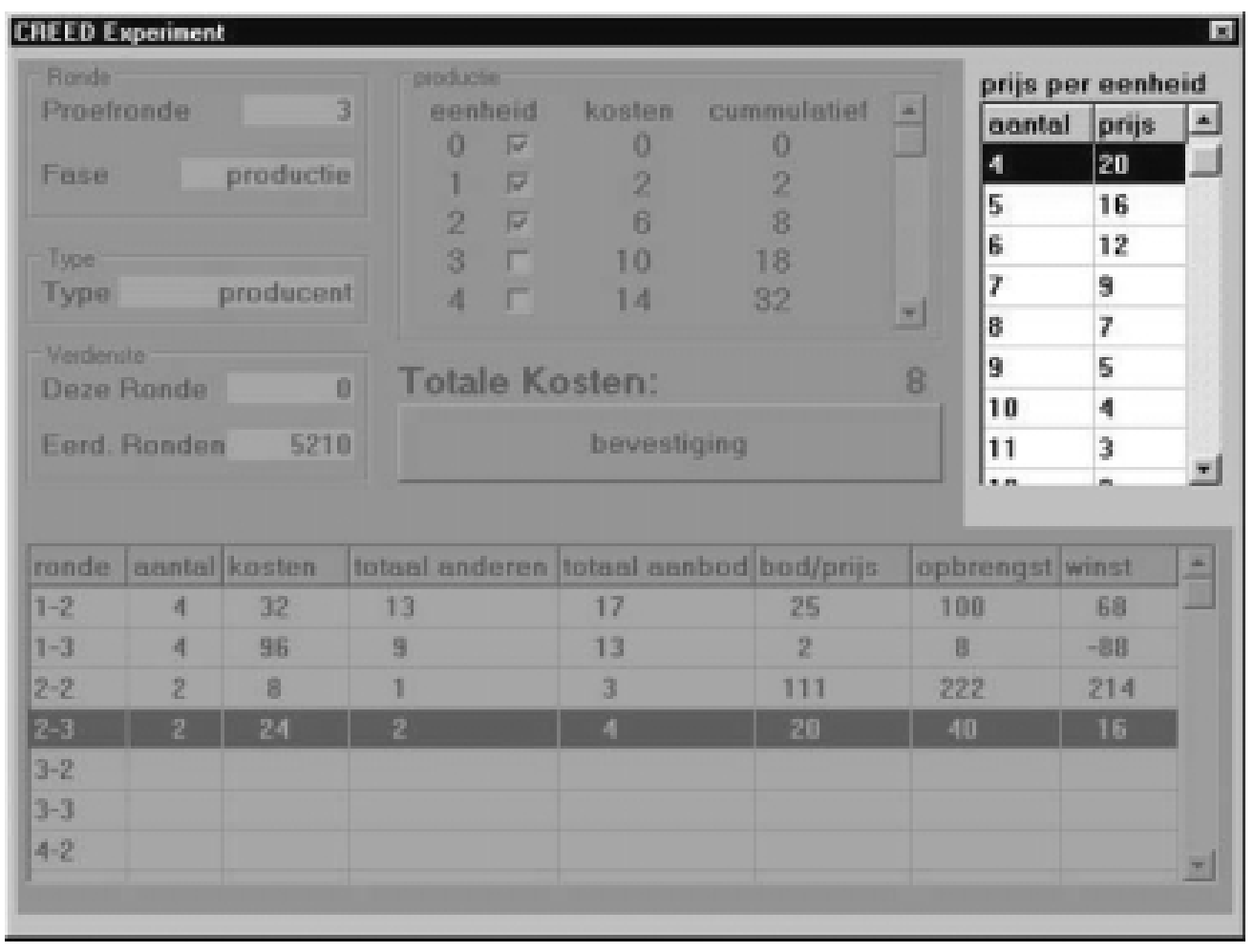

figure 1: Table with the per unit price.

Above, you see an example of the computer screen we will use. The numbers you see will be different in the experiment. Focus on the 'sharp' picture, in the upper right part.

The table you see in the upper right corner is only an example. Later, you will be able to scroll along the table with your mouse, this is not possible in these instructions. You will find a print of the table to be used in the experiment in an envelop on your desk. This table is the same for everyone. You may open the envelop now. For the time being, only have a look at the table 'Price per Unit'.

There are two columns in the table. The left column (with the heading 'number') gives the total supply (of your group). In the right column (with the heading 'price') you see the price PER UNIT that goes with the number supplied. In phase 3 , the computer buys all units offered at this price.

If a group (producers plus traders) offers 8 units in phase 3, for example, each participant in that group will receive 7 francs per unit offered. If you offered 3 of the 8 units, you will get $3 \times 7=21$ francs. Note that the price per unit decreases as the group produces more. 
This is the way in which sales in phase 3 take place. Producers also offer units to traders in phase 1 . This is what we will discuss next.

\section{PHASE 1 and PHASE 2}

In phase 1, all producers decide how many units they would like to offer to the traders. In this phase, they do not know which price they will receive per unit. This depends on what traders bid in phase 2. After every producer has decided how many units to offer to the traders in the group, the total is summed up.

Next, in phase 2, the traders bid a price PER UNIT. The trader with the highest bid receives all units offered at that price. If neither trader bids a price higher than zero, nothing is sold. If there are bids, then all units are produced and delivered. The trader then pays each producer for the goods delivered.

\section{THE PRODUCERS (SELLERS)}

At the beginning of the experiment, each producer will receive 5000 francs as a starting capital. You will see this amount on your screen (at 'previous earnings') when the experiment starts.

There are costs related to producing goods. These costs are not constant per unit, they are increasing. This means that the costs of the second unit are higher than those of the first unit, etc.

NOTICE: The units in phase 1 and 3 add up. For example, someone who produces 3 units in phase 1 and sells them to the traders, starts phase 4 with the fourth unit. This has consequences for production costs.

On the next page, you will see how the costs per unit will appear on your screen.

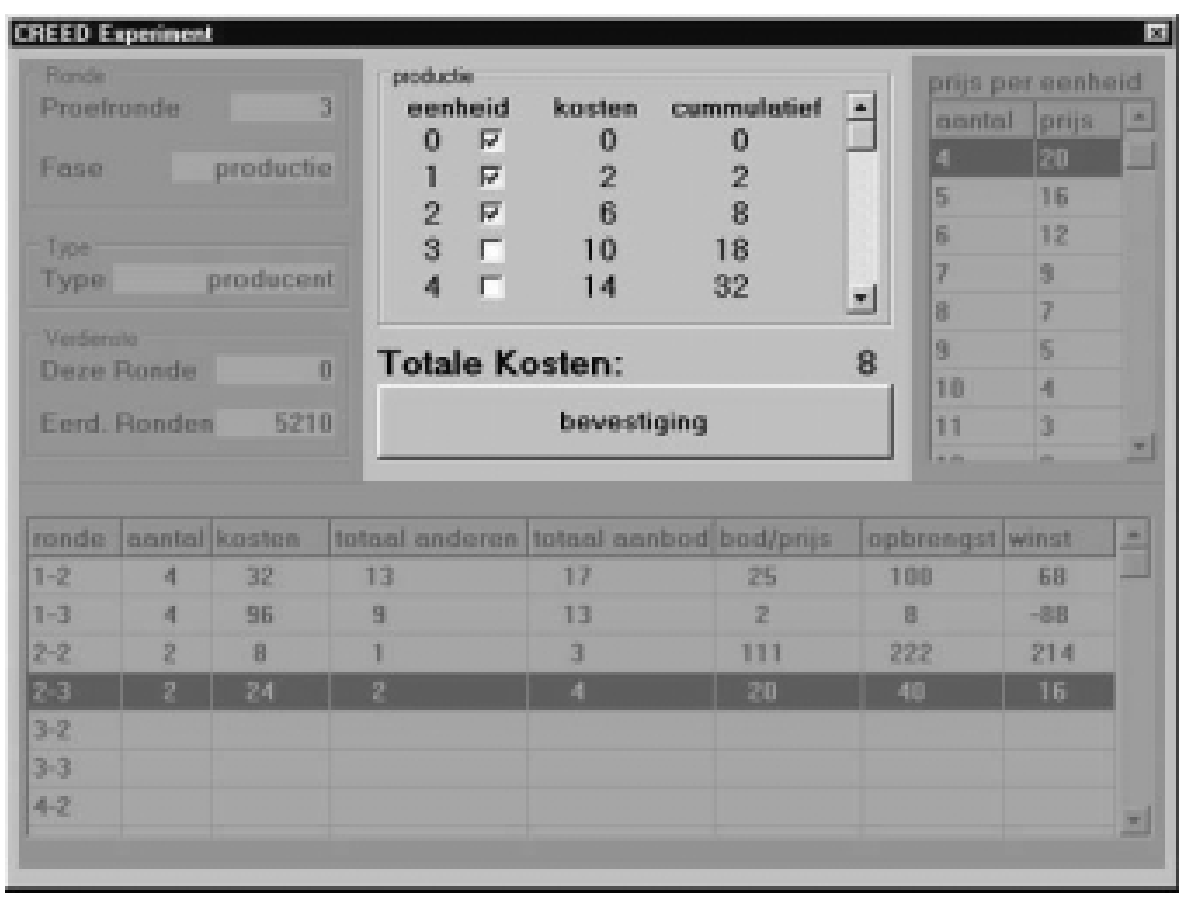

Figure 2: Costs per unit

The table you see above in figure 2 (in the center), is only an example. Later, you will be able to scroll along the table with your mouse, this is not possible in these instructions. You will also find a print of the table to be used in the experiment in an envelop on your desk. Have a look at the table 'Costs per Unit'. This table is the same for everyone. 
In the first column, you see the number you produce ('unit'). The second column ('costs') gives the costs of that unit. You cannot produce a unit without producing the preceding ones. For example, if you want to produce the fifth unit, you must also produce the first, second, third and fourth units. Note that the costs are only determined by your own production. In no way are your costs affected by what other producers in your group do. Your costs in phase 3 do depend on your own production in phase 1 .

To determine the total costs of a certain level of production, you must add up the costs of every unit. To help you calculate these total costs, you will find the total costs for the number of units produced under 'cumulative'.

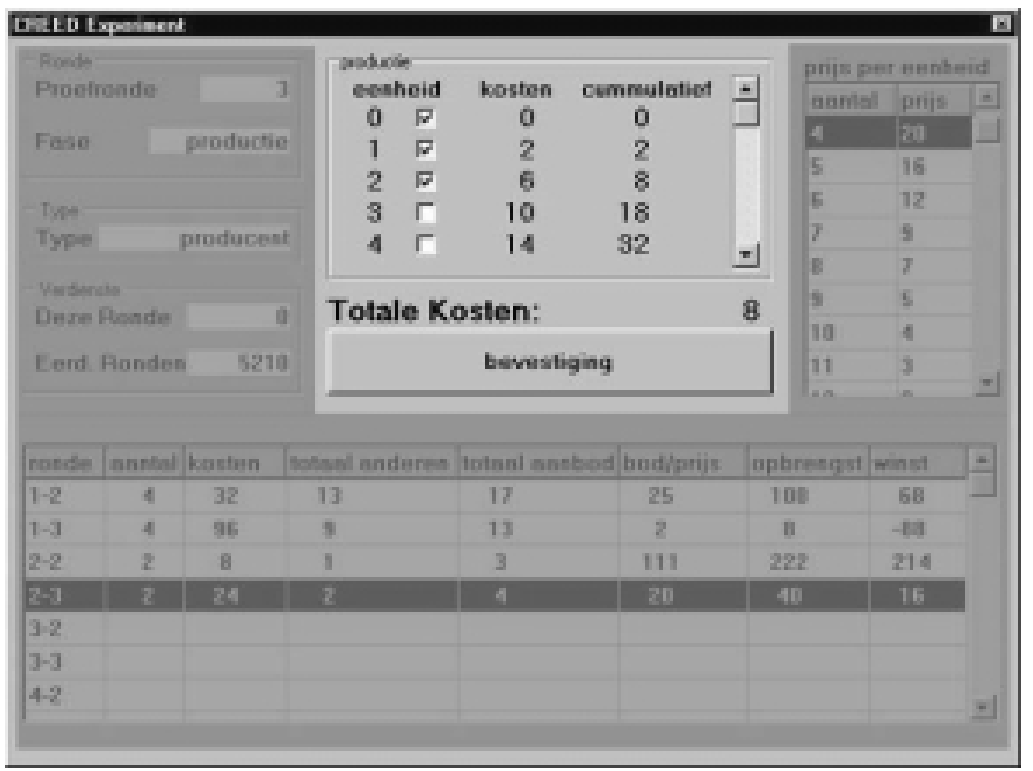

Figure 2: Costs per unit

In the table on your screen that gives the costs, you will also be able to indicate your production decision. This holds in both phase 1 and phase 3 . You do this by clicking one of the numbers under 'sell'. If you click 3, for example, you indicate that you want to produce and sell 3 units (to be more precise, units 1, 2 and 3 ). These three units will therefore be marked, if you click on 3.

In phase 3, you will see that the units you sold in phase 1 can no longer be chosen. For example, if you sold 3 units to the trader, you can only click on 4,5 , etc.

Each producer can sell (in phase 1 and 3 together) a maximum of 30 units per round.

After you have chosen a number, you need to confirm. This holds in both phase 1 and phase 3 . As long as you have not confirmed, you can still change your decision. Note that you decision is not final until you have confirmed it. The experiment will not proceed to the next phase until everyone has confirmed his or her production decision. You also need to confirm if you decide to produce zero units.

In phase 2, producers do not need to make a decision. They must wait until the traders have decided at what price they are willing to buy the goods produced. At the end of phase 2 every producer will receive for every unit produced the amount determined by the traders.

\section{THE TRADERS}

At the beginning of the experiment, each trader will receive a starting capital of 45000 francs. In addition, each trader will receive 2000 francs in each round. You will see these amounts on your screen when the experiment starts (at 'previous earnings'). 
A trader cannot produce goods, but can buy them in phase 2, depending on the supply by the producers in her or his group in phase 1 . The trader must then indicate at which price PER UNIT he or she is willing to purchase these goods. How this is done is explained on the next page.

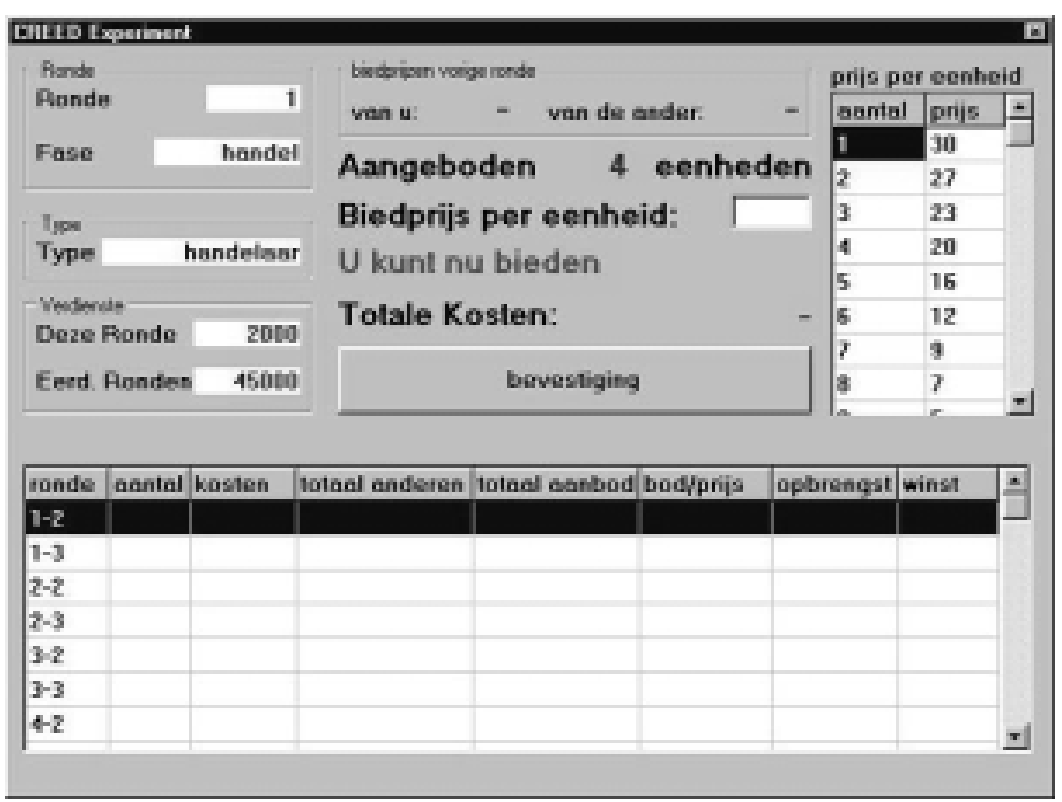

Figure 3: Phase 2

Traders are told what the total supply by their group's producers is in phase 1 . Then, each trader bids an amount per unit. For example, if 10 units are offered, this means that a bid of 3 francs implies a total bid of 30 francs. The bid must be confirmed to make it final.

After all traders have decided, for each group it is determined which trader has made the highest bid. This trader receives all of the goods from this group, the other trader receives nothing. If the bids are equal, a lottery determines the winner.

Every trader must make a bid.

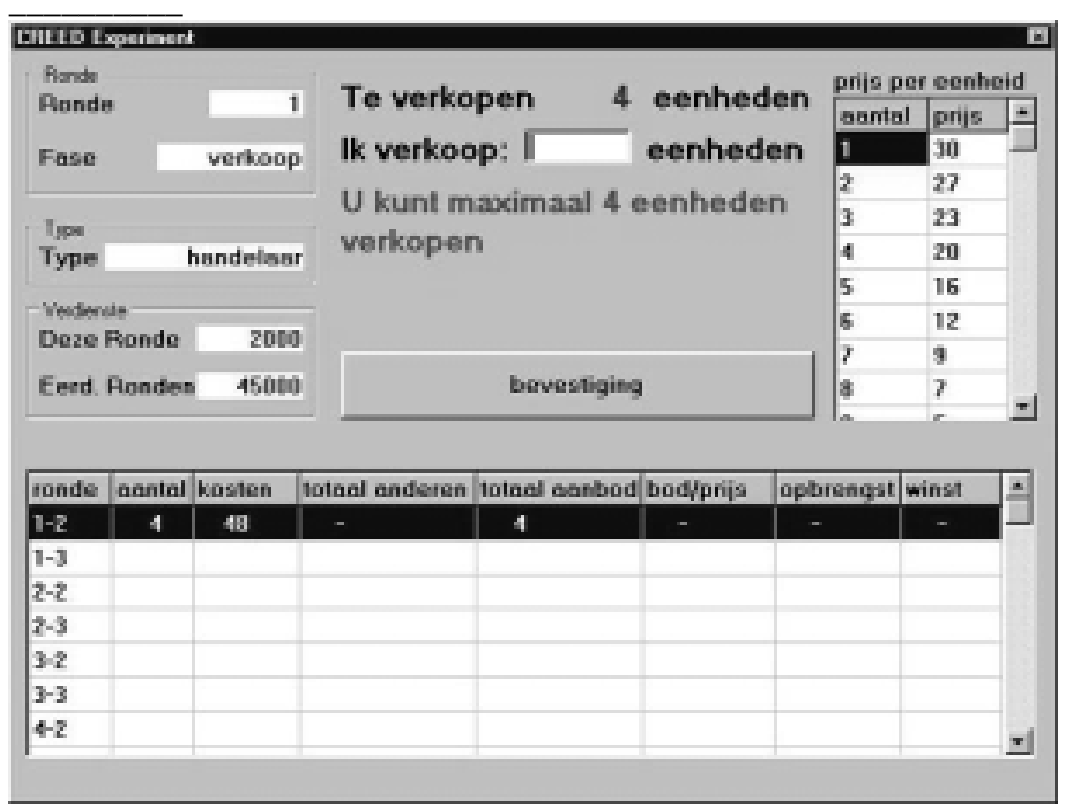

Figure 4: Phase 3 
In phase 3, the traders can offer the goods they bought for sale to the (simulated) buyers. They are not required to sell all of the units bought. It does hold that they paid for all units bought in phase 2 .

For every unit sold in phase 3 , the trader receives the price determined using the table 'Price per Unit'. As discussed above, this price is also affected by the production of the producers in phase 3 .

Therefore, in phase 2 the trader pays for the goods bought and receives money for the goods in phase 3 , from the buyers (the computer). The difference reflects the trader's earnings.

\section{THE TRANSACTIONS IN PHASE 3}

At the end of phase 3 in each round, the total supply per group is determined. The sales price is determined using the table 'Price per Unit'. Every participant in a group receives as revenue the number of units he or she offered times the price determined by this table.

The information of every round is shown on the lower part of the screen at the end of the round. On the following page, you can see how this is done.

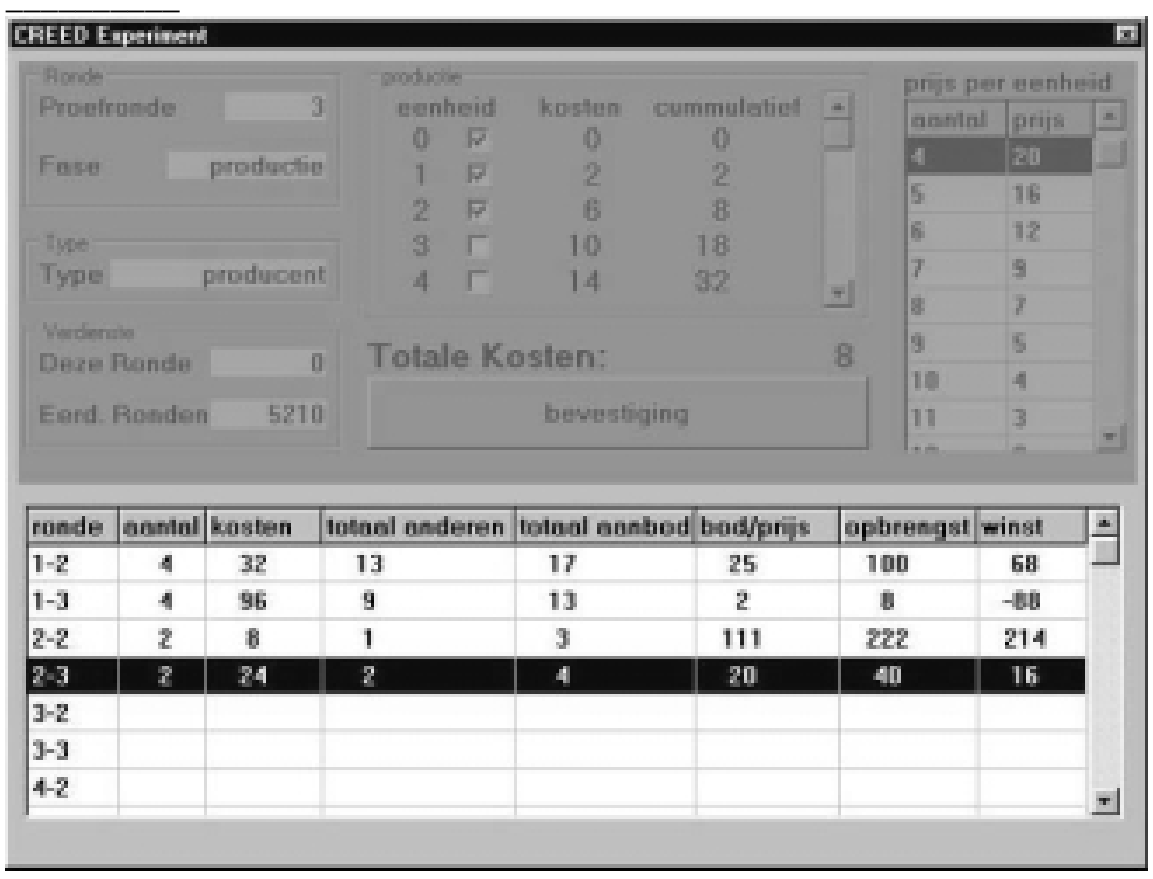

Figure 5: The results of a round

The table shows, from left to right:

round: the number of the round; this consists of two rows. The first row refers to phases 1 and 2; the second row is for phase 3 .

number: for producers: the number of units (per phase) that you have produced; for traders: the number of units you have bought in phase 2 .

costs: for producers: the (total) costs (per phase) of the goods you produced; for traders: your total costs (the price bid times the number of units bought).

total the total number of units that others in your group have produced or supplied.

others:

total the aggregate supply in your group (number + total others)

supply:

bid/price: the price per unit in your group 
revenue: for producers: (per phase) the price per unit times the number of units you produced; for traders: the price per unit times the number of units you supplied in phase 3 ;

earnings: your profit or loss in the round (revenue - costs).

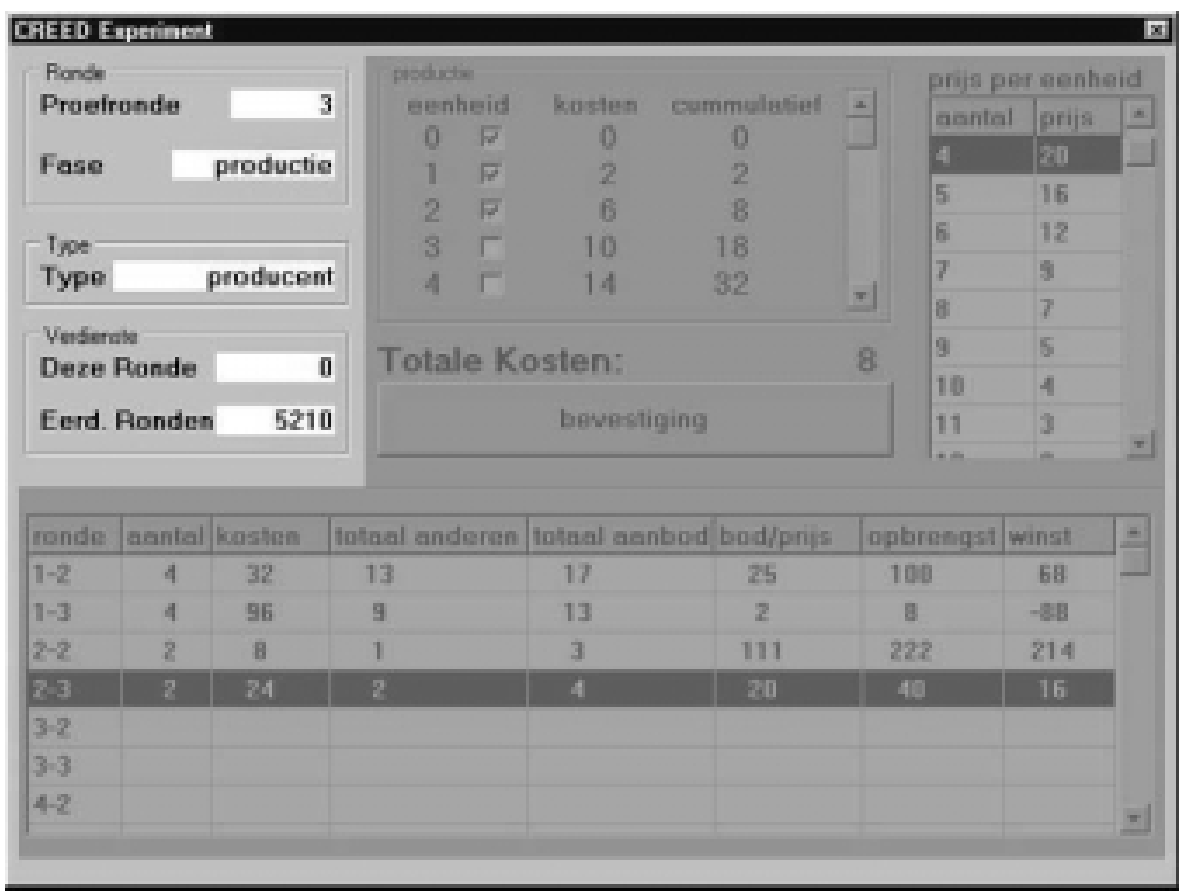

Figure 6: The results thus far

At the end of a round, the profit or loss is added to your earnings thus far. This is shown in the upper left area on your screen, with the earnings in this round.

You may lose money in a round. If your aggregate earnings should become negative, you will be excluded from further participation in the experiment and you will not be able to produce or trade any more goods. You will go home without earnings. It is under your own control whether or not you lose money.

You have reached the end of these instructions. You may take your time to go through them again. Please wait quietly until everyone has finished. 


\section{Appendix 2}

In this appendix, we derive the theoretical predictions given in table 3 of the main text. We do so in two steps. First, we derive the predictions for a continuous version of the game. Then, we use these as a double check for the predictions numerically estimated for the case where players can only choose discrete quantities.

\section{Continuous Case}

We extend the duopoly model of Allaz and Vila (1993) to oligopolies with $n$ producers and (symmetric) quadratic marginal cost functions, $M C\left(q_{i}\right)=c q_{i}^{2}$. Total costs are then $C\left(q_{i}\right)=2 \sum_{i=1}^{q_{i}} l^{2}$ $=\frac{2}{3} q_{i}^{3}+q_{i}^{2}+\frac{q_{i}}{3}$. Market demand is known and linear in quantities: $P(Q)=a-b \cdot Q$ with $Q=\sum_{i=1}^{n} q_{i}$

The relation between the forward contract market and the spot market is modeled as a two-stage game. In the first stage the producing firms take positions in the contract market represented by $f_{i}$, $\mathrm{i}=1,2, . . \mathrm{n}$. In doing so, they take account of the equilibrium prediction that traders will supply to the spot market everything they obtain on the forward market. Hence, in equilibrium, supply to the spot market is equal to total production.

Producer $i$ 's profit for the second stage, when producing $q_{i} \geq f_{i}$, is then given by:

$$
\Pi_{i}=\left(a-b \cdot \sum_{i=1}^{n} q_{i}\right) \cdot\left(q_{i}-f_{i}\right)-\frac{2}{3} q_{i}^{3}-q_{i}^{2}-\frac{q_{i}}{3} .
$$

which gives the first order conditions:

$$
\partial_{q_{i}} \Pi_{i}=0 \Leftrightarrow-b \cdot\left(q_{i}-f_{i}\right)+\left(a-b \cdot \sum_{i=1}^{n} q_{i}\right)-2 q_{i}^{2}-2 q_{i}-\frac{1}{3}=0, q_{i} \geq f_{i},
$$

To determine the equilibrium quantities $\left(\tilde{q}_{1}, \tilde{q}_{2}, \tilde{q}_{3}\right)$ to be produced in stage 2 , we solve the system of equations (A1) in terms of producers' forward market positions $f_{1}, f_{2}, f_{3}$. The solution to (A1) has no analytical expression and is numerically determined. It has 8 roots, but only one of them, $\tilde{q}_{1}, \tilde{q}_{2}, \tilde{q}_{3}$, leads to three non-negative forward positions. These quantities (as functions of $f_{1}, f_{2}, f_{3}$ ) determine the equilibrium price $P(\tilde{Q})=a-b \cdot \sum_{i=1}^{n} \tilde{q}_{i}$. 
Moving to stage 1, we proceed with determining (numerically) the quantities supplied to the forward market. At stage 1, producers know that (in equilibrium) traders will bid the (spot) market equilibrium price for the units on the forward market. The producers' profit (as a function of forward positions and anticipated stage 2 reactions) is then given by:

$$
\pi_{i}=P\left(\tilde{Q}\left(f_{i}, F_{-i}\right)\right) . \tilde{q}_{i}\left(f_{i}, F_{-i}\right)-\frac{2}{3}\left[\tilde{q}_{i}\left(f_{i}, F_{-i}\right)\right]^{3}-\left[\tilde{q}_{i}\left(f_{i}, F_{-i}\right)\right]^{2}-\frac{\tilde{q}_{i}\left(f_{i}, F_{-i}\right)}{3},
$$

where $F_{-i}$ denotes the aggregated forward positions of the other producers. Taking the first order conditions $\partial_{f_{i}} \pi_{i}\left(f_{i}, F_{-i}\right)=0$ and solving for $f_{i}$, we derive the producers' equilibrium forward positions $f_{1}^{*}, f_{2}^{*}, f_{3}^{*}$, which are used to determine the equilibrium spot market production levels $\tilde{q}_{1}, \tilde{q}_{2}, \tilde{q}_{3}$ and the market price $P(\tilde{Q})$.

If there is no forward contract market, then $f_{i}=0$ and (A1) boils down to the standard Cournot profit maximization program. Table A reports the numerically determined Nash equilibria for C3.0, C3.2, C4.0 as well as the joint profit maximizing (JPM) and Walras (W) scenarios with 3 and 4 producers. The JPM and $\mathrm{W}$ cases are determined in the standard way.

Table A: Benchmarks for the Continuous Case ${ }^{\mathrm{a}}$

\begin{tabular}{lccccccc}
\hline & $\begin{array}{l}\text { JPM } \\
(\mathbf{n = 3})\end{array}$ & $\begin{array}{c}\text { JPM } \\
(\mathbf{n}=\mathbf{4})\end{array}$ & $\begin{array}{c}\mathbf{N E} \\
\mathbf{C 3 . 0}\end{array}$ & $\begin{array}{c}\mathbf{N E} \\
\mathbf{C 3 . 2}\end{array}$ & $\begin{array}{c}\mathbf{N E} \\
\mathbf{C 4 . 0}\end{array}$ & $\begin{array}{c}\text { Walras } \\
(\mathbf{n = 3})\end{array}$ & $\begin{array}{c}\text { Walras } \\
(\mathbf{n = 4})\end{array}$ \\
\hline$q_{t i}^{f}$ & --- & --- & -- & 5.736 & --- & --- & -- \\
$q_{t i}$ & 10.777 & 8.509 & 14.406 & 15.320 & 12.364 & 17.071 & 14.406 \\
$q_{t}$ & 32.330 & 34.034 & 43.217 & 45.959 & 49.457 & 51.212 & 57.623 \\
$p_{t}$ & 1127.08 & 1081.07 & 833.143 & 759.112 & 664.652 & 617.283 & 444.190 \\
Prod.S. & 33576.5 & 34850.0 & 29389.9 & 26977.7 & 27203.4 & 20772.0 & 16774.1 \\
Cons.S. & 14110.8 & 15637.6 & 25214.0 & 28514.9 & 33021.3 & 35405.6 & 44824.9 \\
Total $S$. & 47687.3 & 50488.1 & 54603.9 & 55492.6 & 60224.7 & 56177.6 & 61599.0 \\
Eff. $(\%)$ & 84.9 & 82.0 & 97.2 & 98.8 & 97.8 & 100 & 100 \\
\hline a $q_{t i}^{f}=$ forward production by producer $i ; \quad q_{t i}=$ total quantity produced by producer $i$; $q_{t}=$ total \\
quantity produced in the market; $p_{t}=$ transaction price; prosur=producer surplus (trader surplus is equal \\
to 0); consur= consumer surplus; surplus=total surplus; eff= efficiency.
\end{tabular}




\section{Discrete Case}

As subjects in our experiment could only supply integer quantities, we base our data analysis on the equilibrium outcomes for the discrete case. This is determined using the GAMBIT software (McKelvey, McLennan and Turocy, 2002). ${ }^{23}$

We start with the cases without a forward market (C3.0 and C4.0). Given the large strategy sets (i.e., 30 possible actions per producer), which would require a considerable time and computing facilities to explore all possibilities, we searched for equilibria in windows of 20 units (i.e., for $q_{t i} \in[0,19], \quad q_{t i} \in[1,20], \quad q_{t i} \in[2,21]$, etc. Using this method, we found equilibria in pure strategies. In C3.0, the equilibria entail any two producers supplying 14 units and the third producer supplying 15 units. In aggregate they produce 43 units equilibrium (compare this to the equilibrium production of 43.217 units in the continuous case; $c f$. table A). In C4.0, three producers supply 12 units in equilibrium and the fourth supplies 13 units, for a total of 49 (49.457 in the continuous case). These numbers are reported in table 3 of the main text.

For C3.2, we restrict the window size for the equilibrium search in GAMBIT to 4 units for the forward market and 5 units for the spot market (e.g., we search for $q_{t i}^{f} \in[0,3]$ and $q_{t i}-q_{t i}^{f} \in[0,4]$, $q_{t i}^{f} \in[1,4]$ and $q_{t i}-q_{t i}^{f} \in[0,4]$, etc.). In addition, we reduced the two-stage game to its normal form and searched for an equilibrium of the type $\left(q_{t i}^{f}, q_{t i}-q_{t i}^{f}\right)$ in pure and mixed strategies. The equilibrium that we found when quantities are discrete is partially in mixed strategies: each producer supplies six units on the forward market. On the spot market, each producer supplies 9 units with probability .944343 or 10 units with probability .055657 . This yields a total (expected) supply of 45.167. This is slightly lower than the equilibrium quantity for the continuous case (45.959).

\footnotetext{
${ }^{23}$ The JPM and W predictions for the discrete case are determined in a straightforward manner.
} 